\title{
Deutschunterricht und Germanistikstudium an der Philosophischen Fakultät in Zagreb 1876-1904
}

Die Abteilung für Germanistik ist heute eine der größten an der Philosophischen Fakultät der Universität Zagreb, doch zu ihrer Geschichte vor allem über die Zeit vor dem Zweiten Weltkrieg - liegen bisher nur wenige Forschungsarbeiten vor. ${ }^{1}$ Antun Sedlar, Assistent im Seminar für deutsche Philologie, stellte in seinem 1941 in der Münchner Zeitschrift "Deutsche Kultur im Leben der Völker« veröffentlichten Artikel die Entwicklung der Zagreber Germanistik dar. ${ }^{2}$ Auch neuere Beiträge zur Institutionsgeschichte wurden von Professoren der Zagreber Germanistik verfasst. In den Darstellungen von Viktor Žmegač $\check{c}^{3}$ und Marijan Bobinac $c^{4}$ liegt der Schwerpunkt auf der Entwicklung der Zagreber Germanistik nach 1945 im kroatischen und
In der analytisch orientierten historiographischen Interpretation der Entstehung und Entwicklung des Lektorats für deutsche Sprache und des Lehrstuhls für deutsche Philologie an der Philosophischen Fakultät der Universität Zagreb wird versucht, mithilfe von Quellen aus dem Archiv der Fakultät sowie der Referenzliteratur die ersten dreißig Jahre des universitären Deutschunterrichts im Detail und unter Berücksichtigung der historischen und sozialen Kontexte in Zagreb, Banal-Kroatien und in der Doppelmonarchie zu rekonstruieren.

1 An der Philosophischen Fakultät der Universität Zagreb (in der Folge abgekürzt: FFZG) gibt es heute 23 Abteilungen und mehr als 100 Lehrstühle. Im akad. Jahr 2014/15 betrug die Zahl der Studierenden 5738. Die Abteilung für Germanistik zählte 370 Studierende und über 30 Angestellte in Forschung und Lehre. Vgl. die im Literaturverzeichnis unter »Internetquellen « angeführten Texte.

2 Sedlar: Germanistik in Kroatien.

3 Žmegač: Zur Geschichte der Germanistik in Kroatien.

4 Bobinac: Odsjek za germanistiku. 
mitteleuropäischen Kontext. Bezüglich des Zeitraumes von 1876 bis 1918 berufen sich beide auf Sedlars faktographische Angaben. ${ }^{5}$

In den letzten Jahren ist ein verstärktes Interesse der kroatischen Geschichtsschreibung für die Geschichte der Universität Zagreb im weitesten Sinne, d.h. für Studierende, Lehrkräfte, institutionelle Rahmenbedingungen usw. zu verzeichnen. Das Desiderat ist besonders in Bezug auf die Entwicklung der Germanistik groß. Die vorliegende Arbeit setzt sich daher zum Ziel, einen Beitrag zur Erforschung der Geschichte der Zagreber Germanistik zu leisten, insbesondere zu der am wenigsten bekannten Anfangsphase. Sie basiert im Wesentlichen auf der systematischen Auswertung bisher unerschlossener Quellen aus dem Archiv der Fakultät sowie der vorhandenen Sekundärquellen. Im Mittelpunkt der Arbeit stehen die Veränderungen der rechtlichen und institutionellen Rahmenbedingungen des Deutschunterrichts bzw. des Studiums der deutschen Sprache und Literatur, der Wandel von Curricula und Unterrichtspraxis sowie die Akteure dieser Entwicklungen. Die Entwicklung des Deutschunterrichts und des Germanistikstudiums an der neu gegründeten Universität wird dabei im Zusammenhang mit den gesamtgesellschaftlichen und sprachpolitischen Veränderungen in der zweiten Hälfte des 19. Jahrhunderts untersucht.

Folgende Fragen stehen im Vordergrund: Inwieweit folgte das ursprüngliche Konzept des universitären Deutschunterrichts den gesellschaftlichen Bedürfnissen? In welchen Momenten wurde es überarbeitet bzw. aktualisiert? Und schließlich: Inwieweit folgte die institutionelle Entwicklung der Germanistik in Zagreb der Entwicklungsdynamik an anderen mitteleuropäischen Universitäten?

\section{Deutsche Sprache und Sprachpolitik in Banal-Kroatien im langen 19. Jahrhundert}

Nach der Wiederherstellung des Konstitutionalismus in der Habsburgermonarchie durch das Oktoberdiplom 1860 gerieten die kroatischen politischen und kulturellen Eliten hinsichtlich ihrer Sprachpolitik in ein

5 Auch Zdenko Škreb (1904-1985), der die Nachkriegsentwicklung der Zagreber Germanistik maßgeblich prägte, soll in seinem für die Enciklopedija Jugoslavije (Enzyklopädie Jugoslawiens) verfassten Text einen ausführlichen Überblick über die Geschichte der Zagreber Universitätsgermanistik geboten haben. Vgl. Mojašević: Nemačko-jugoslovenske kulturne veze, S. 251. Mojašević will eine Kopie dieses Textes von Škreb bekommen haben. In der Enzyklopädie erscheint jedoch nur ein knapper Beitrag über Stjepan Tropsch, ohne Angabe des Verf. Vgl. Tropsch, Stjepan, S. 375 . 
Dilemma: Nachdem das grundlegende Problem der modernen kroatischen Standardsprache gelöst worden war, stellte sich die Frage, wie diese Sprache weiter zu entwickeln sei, sowohl auf dem philologischen Gebiet als auch im Bereich der praktischen Anwendung. ${ }^{6}$ Dabei spielte auch die Einstellung gegenüber anderen Sprachen eine wichtige Rolle.

Die kroatischen Länder gehörten zu einem Raum, der von zwei Sprachen geprägt war: Italienisch und Deutsch. Letztere war in Mitteleuropa, also auch in Nordkroatien vertreten, mit der Tendenz, sich nach Ost- und Südosteuropa und sogar bis nach Russland zu verbreiten. ${ }^{7}$ Da sich die Zentren der kroatischen Nationsbildung in Zagreb und in anderen kroatischen kontinentalen Städten befanden, konnte sich das entlang der kroatischen Adriaküste verbreitete Italienische kaum durchsetzen. Der Großteil des kroatischen Territoriums lag innerhalb des deutschsprachigen Einflussbereichs, vor allem seit der zweiten Hälfte des 18. Jahrhunderts, als der Einfluss oft durch staatliche Maßnahmen verstärkt wurde. ${ }^{8}$ Seit 1790 waren in der kroatischen Gesellschaft und Kultur systematische Magyarisierungs- und Germanisierungsversuche zu verzeichnen, die in mehreren Etappen verliefen. ${ }^{9}$

Durch das Patent von Joseph II. wurde 1784 Deutsch als Amtssprache in Banal-Kroatien eingeführt. Obwohl es bereits 1790 widerrufen wurde, waren seine Auswirkungen weitreichend. ${ }^{10}$ Erst 1847, als Ergebnis der Kroatischen Nationalen Wiedergeburt (der illyrischen Bewegung), wurde das Kroatische vom Sabor, dem kroatischen Landtag, zur Amtssprache in Banal-Kroatien erklärt. Auf den >Völkerfrühling 1848 folgte jedoch eine neue Germanisierungswelle, zunächst mit der Oktroyierten Märzverfassung. Das Kroatische blieb »die Geschäftssprache der lokalen Behörden«, doch diese mussten mit den Behörden der anderen Kronländer und mit dem Wiener Zentrum auf Deutsch kommunizieren. Zur offenen Germanisierung kam es wieder ab 1854, als Deutsch in allen Behörden und an allen Schulen zur einzigen Amtssprache wurde. ${ }^{11}$ Im Gebiet der kroatisch-slawonischen Militärgrenze war bis zur ihrer Auflösung und Eingliederung in Banal-Kroatien (1881)

6 Vgl. Vince: Putovima hrvatskoga književnog jezika, bes. S. 529-602.

7 Vgl. Bilington: Ikona i sekira, S. 212-545.

8 Unter dem stärksten Einfluss sahen sich jene Gebiete Kroatiens, die unter der unmittelbaren Verwaltung der Hofkammer oder des Hofkriegsrats standen. In Banal-Kroatien diente der habsburgische aufgeklärte Absolutismus von 1765 bis 1790 als mehr oder weniger offenes Mittel der Germanisierung.

9 Vgl. Kessler: Politik, Kultur und Gesellschaft, bes. S. 134-217.

10 Vgl. Strecha: O pitanju utjecaja bečkog središta (mit ausführlichen Literaturhinweisen).

11 Vgl. Valentić u.a. (Hgg.): Povijest Hrvata, S. 419-424. 
Deutsch die einzige Amtssprache. ${ }^{12}$ Während des mehrjährigen Auflösungsprozesses wurde Kroatisch schrittweise eingeführt. ${ }^{13}$

Zahlreiche deutschsprachige Wörter und kroatisierte Formen fanden ihren Weg in die Alltagssprache, von denen sich viele einbürgerten. ${ }^{14}$ Auch viele terminologische Desiderata wurden mithilfe des Deutschen gelöst. ${ }^{15}$ All dies führte dazu, dass die kroatische Stadtkultur des 18. und der ersten Hälfte des 19. Jahrhunderts von der deutschen Sprache und der deutschen Kultur tief durchdrungen war. ${ }^{16}$

Nach 1859 war die Einstellung in Banal-Kroatien gegenüber der deutschen Sprache erwartungsgemäß kritisch oder bestenfalls ambivalent. Die negativ gewertete Rolle >der Deutschen` während des >Bach'schen Systems konnte, trotz aller positiv bewerteten Einflüsse des deutschsprachigen Raums, nicht vergessen werden. ${ }^{17}$ Deswegen schlugen einige Abgeordnete im kroatischen Landtag von 1861 vor, das Pflichtfach Deutsch an den Schulen durch Französisch zu ersetzen, denn das Französische stimme mehr mit dem kroatischen Geist überein als das Deutsche. Eine überaus kleine Minderheit plädierte dagegen für die Einführung von Ungarisch beziehungsweise Italienisch als Pflichtfach. Dabei ging es im Grunde - wie einer der Diskussionsteilnehmer resümiert - um den »Konflikt zwischen dem Herzen und dem Verstand «. ${ }^{18}$

Es wurden zahlreiche Argumente zugunsten des ।Verstandes ` vorgetragen: so wurde beispielsweise betont, das Lernen der deutschen Sprache an Gymnasien sei notwendig, denn die deutsche Literatur sei klassisch geprägt und das Ziel der Gymnasien bestünde darin, die Klassizität zu fördern. Die Meisterwerke deutscher Literatur seien ein wichtiger Bestandteil der europäischen Kulturgeschichte und Wissensquelle für viele kroatische Gelehrte. Einige warnten davor, dass viele Kroaten ohne auf dem Bildungsweg erworbene Deutschkenntnisse die Möglichkeit zum Studium an ausländischen Universitäten verlieren würden..$^{19}$ Einige vertraten die Meinung, durch den Deutschunterricht könnte bei den Schülern die Liebe zur Muttersprache, Heimatliebe und Stolz geweckt werden, denn die deutsche Sprache sei `schwächer`als die kroatische, da sie

$12 »$ Die Dienst- und Amtssprache in der Militairgrenze ist durchaus die deutsche; in ihr werden alle Befehle erlassen, alle Vorträge und Rapports abgefaßt, und das Exerzierreglement ist ganz deutsch«. Pirch: Caragoli, Bd. 1, S. 207.

13 Vgl. Valentić: Vojna krajina, S. 277, 284, 296 u. 318.

14 Vgl. Glovacki-Bernardi u.a. (Hgg.): Agramer; Petrović: Esekerski rječnik; Piškorec: Germanizmi u govorima đurđevečke Podravine.

15 Vgl. Šulek: Deutsch-kroatisches Wörterbuch; ders.: Hrvatsko-njemačko-talijanski rječnik znanstvenog nazivlja.

16 Roksandić: Kontroverze o njemačkoj kulturnoj orijentaciji, S. 69.

17 Taylor: Habsburška monarhija 1809-1918, S. 108.

18 Vgl. Dnevnik Sabora trojedne kraljevine, S. 808-814 u. 815-817.

19 Ebd., S. 809. 
anstelle von sieben grammatischen Fällen nur vier aufweist. In der hitzigen Debatte war zu vernehmen, die deutsche Sprache sei dem kroatischen Geiste fremd und alle Fremdsprachen seien gefährlich. Ungeachtet aller Warnungen wurde beschlossen, das Deutsche durch keine andere Sprache zu ersetzen. ${ }^{20}$ Mit der Entscheidung, Deutsch als Pflichtfach an den Schulen zu unterrichten, war die Frage der kroatischen kulturellen Orientierung im Grunde gelöst. Nach acht Jahren des gymnasialen Deutschunterrichts - wobei zu betonen ist, dass das Deutsche bezüglich der Wochenstundenzahl der Muttersprache fast gleichgestellt war - konnte selbstverständlich keine andere lebende Fremdsprache die Dominanz des Deutschen im öffentlichen, kulturellen und wissenschaftlichen Bereich gefährden. ${ }^{21}$

\section{Julije Šajatović: der erste Deutschlehrer an der Philosophischen Fakultät in Zagreb (1876-1886)}

In den Diskussionen über die erst zu gründende Universität (1861-1874) lag ein besonderer Akzent auf der Frage, wie sie im Sinne der Gewährleistung einer vielseitigen geistigen und materiellen Entwicklung für das kroatische Volk zu entwickeln ist. ${ }^{22}$ Dies war eine Aufgabe, die sie mit der Jugoslawischen Akademie der Wissenschaften und Künste hätte teilen sollen. ${ }^{23} \mathrm{Im}$ Hinblick auf die Errungenschaften der modernen Naturwissenschaften trachtete man danach, mit den ausländischen Universitäten Schritt zu halten. An der philosophisch-geschichtlichen Abteilung der Philosophischen Fakultät fand sich dagegen damals kein Interesse an einem wissenschaftlichen Ansatz zu philologisch-sprachlichen Problemen der lebenden Sprachen, mit Ausnahme der Kroatistik und Slawistik. ${ }^{24}$

So wurde den Schülern bspw. 1886 in den ersten vier Klassen einer Realschule wöchentlich vier Stunden Kroatischunterricht vorgeschrieben, in der fünften Klasse drei und in der sechsten und siebten zwei. Deutsch wurde vier Stunden in der ersten Klasse gelernt, die nächsten vier Jahre drei und schließlich zwei Stunden in der sechsten und siebten Klasse. Französisch konnte in der fünften, sechsten und siebten Klasse jeweils zwei Stunden gelernt werden. Vgl. Naredba kr. hrv.-slav.-dalm. zemaljske vlade, S. 12; Naučna osnova za srednje škole; Batinić/Vavra: Fremdsprachenunterricht in den kroatischen Schulen im 20. Jahrhundert, S. 24.

22 Die Antrittsrede des ersten Rektors M. Mesić bei der Eröffnung der Universität am 19. Oktober 1874. Vgl. Šidak (Hg.): Spomenica u povodu proslave 300-godišnjice Sveučilišta u Zagrebu, S. 370.

23 Gross/Szabo: Prema hrvatskome građanskom društvu, S. 415-417.

24 An der neu gegründeten Philosophischen Fakultät wurden 1874/75 sechs Lehrstühle eingerichtet: Philosophie, Allgemeine Geschichte, Kroatische Geschichte, Slawische Philologie, Latinistik und Gräzistik. Sechs Professoren hielten Vorlesungen für insgesamt 26 Studenten (23 regelmäßige und 3 außerordentliche). Vgl. Sveučilište Kraljevine Srba, Hrvata i Slovenaca, S. 237 u. 253; Šidak (Hg.): Spomenica u povodu proslave 300-godišnjice Sveučilišta u Zagrebu, S. 349. 
Ein Gesetzesartikel des kroatischen Landtags zur Universitätsorganisation von 1874 schrieb vor, dass die lebenden Sprachen an der Fakultät nur "für praktische Zwecke« zu lehren sind. ${ }^{25}$ Der Deutschunterricht begann im Sommersemester 1875/76. Damit war Deutsch die erste lebende Fremdsprache, die an der Philosophischen Fakultät in Zagreb unterrichtet wurde; in der Folge kamen Russisch, Ungarisch, Französisch, Tschechisch, Italienisch und Englisch hinzu. ${ }^{26}$

Die Universitätsprofessoren waren gleichzeitig Lehrer, Forscher und Theoretiker ihrer Disziplinen. ${ }^{27}$ Deutsch und die anderen lebenden Fremdsprachen wurden dagegen von »Lehrern im engeren Sinne« unterrichtet. ${ }^{28}$ Auch nach ihrer Berufung an die Fakultät lehrten sie weiterhin an den Schulen, an denen sie bis dahin gearbeitet hatten. Für ihren Unterricht an der Fakultät erhielten sie eine jährliche Belohnung. Die Beschäftigung mit wissenschaftlicher Arbeit war nicht vorgesehen, wohl aber die kontinuierliche Kenntnisnahme der Entwicklung von Sprache und Literatur. ${ }^{29}$ Der erwähnte Gesetzesartikel geht nicht näher auf curriculare Fragen ein, jedoch kann anhand der Vorlesungsverzeichnisse rekonstruiert werden, dass der Unterricht sowohl den Erwerb von grammatikalischen Kenntnissen als auch die Behandlung von Themen aus dem Bereich der deutschen Literatur umfasste. Angesichts der Tatsache, dass jede Person mit einem Gymnasialabschluss zumindest über die Grundkenntnisse der deutschen Sprache verfügte, war es nicht nötig, sie ‘ab ovo zu lehren, wie es gewöhnlich der Fall war beispielsweise beim Ungarischen. ${ }^{30}$

Der erste Deutschlehrer an der Philosophischen Fakultät in Zagreb war Julije Šajatović. ${ }^{11}$ Der Zagreber Gymnasiallehrer war dem Fakultätsrat auf-

$$
\text { Sp }
$$
sonders für die künftigen Gymnasiallehrer« (1 Stunde) und »Deutsche Literaturgeschichte von den Romantikern bis zur Jetztzeit, und Lektüre eines Musterdramas der neuesten Litteratur « (2 Stunden). Franjo J. Celestin, Lehrer der slawischen Sprachen, behandelte die Geschichte der modernen russischen Literatur (1 Stunde) und die Geschichte der alten russischen Literatur (1 Stunde). Er las und interpretierte ausgewählte russische Texte (1 Stunde). Andrija Dianiška, der Ungarischlehrer, nutzte zwei Stunden für Vorträge über ungarische Grammatik und eine Stunde für Vorträge über Literatur. Vgl. Akademičke oblasti, WiSe 1880/1, S. $22 \mathrm{f}$.

31 Julije Šajatović (Bjelovar 1842 - Zagreb 1887) war von 1876 bis 1886 Lektor für dt. Sprache an der FFZG. Nach absolviertem Studium in Wien und bestandener Abschlussprüfung im August 1867 konnte er Geschichte und Erdkunde am Unter- und Obergymnasium mit Deutsch als Unterrichtssprache lehren. Ende August 1868 bestand er in Graz die Lehramtsprüfung und 


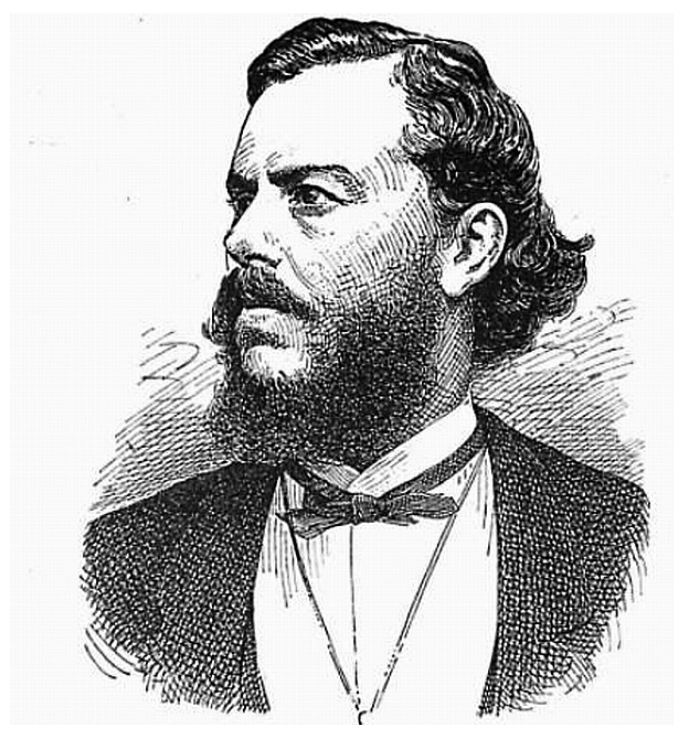

Abb. 1: Julije Šajatović (Quelle: Cuvaj: Građa za povijest školstva, S. 83)

grund einer vorangegangenen Bewerbung für eine Professur am Lehrstuhl für allgemeine Geschichte nicht unbekannt. ${ }^{32}$ Ausschlaggebend bei der Einschätzung seiner Qualifikationen bei der Bewerbung um den Lektorenposten ${ }^{33}$ waren neben den Deutschkenntnissen seine hervorragende Ästhetik- und Literaturkenntnisse sowie seine Lehrerfahrung. ${ }^{34}$ Šajatović war auch als Übersetzer tätig: im Auftrag der kroatischen Landesregierung hatte er drei Bücher aus dem Französischen und Deutschen für den wichtigsten kroatischen Kulturverein Matica Hrvatska übersetzt. Dies wurde als Beleg gewertet, dass er auch auf dem Gebiet der Literatur einen Beitrag zu seinem Fach leisten könne. ${ }^{35}$ Die Mitglieder des Fakultätsrates vertraten die Meinung, Šajatović besitze

wurde »Deutschlehrer am Untergymnasium und an solchem Obergymnasium, wo das Deutsche keine Unterrichtssprache ist«. Im November 1868 wurde er Doktor der Philosophie in Graz. Vgl. AFFZG, Spisi, 1875, o.Nr., Bericht über Jacobi, Schlesinger und Šajatović.

32 AFFZG, Spisi, 1/1874.

33 Neben Šajatović konkurrierten um den Posten: Dr. Hosea Jacobi (geb. 1841 in Jacobshagen) und Anton Schlesinger (geb. 1851 in Alsó-Alap). Jacobi war Oberrabbiner in Zagreb. Trotz seiner hervorragenden Ausbildung qualifizierten ihn seine Dissertation (Über die Stellung des Weibes im Judenthum) und die mündliche Prüfung im Hebräischen für diesen Posten nicht, weil er keine Vorlesungen zur dt. Sprache und Literatur sowie Ästhetik besucht hatte. Schlesinger, Mitarbeiter einiger politischer und satirischer Blätter, konnte keinen Universitätsabschluss aufweisen. Vgl. AFFZG, Spisi, 1875, o. Nr., Bericht über Jacobi, Schlesinger und Šajatović.

34 Ebd. Šajatović war tatsächlich ein erfahrener Lehrer, der seit Jahren am Obergymnasium unterrichtete. Vgl. Program kraljevskoga maloga gimnazija u Karlovcu, S. 19 u. 22; Cuvaj: Građa za povijest školstva, S. 87; Izvěstje o Kraljevskoj višoj gimnaziji u Zagrebu, S. 25, 34 u. 38.

35 AFFZG, Spisi, 1875, o. Nr., Bericht über Jacobi, Schlesinger und Šajatović. 
eine allgemeine humanistische und fachliche Ausbildung, die ihn befähige, Deutsch sowohl im praktischen als auch im theoretisch-wissenschaftlichen Sinne zu lehren. ${ }^{36}$ Neben der mehrjährigen Unterrichtserfahrung sei auch der gute Ruf bei Schülern und Behörden von Bedeutung. ${ }^{37}$

Am 7. Januar 1876 trat Šajatović den Dienst an der Fakultät an, am 29. April begann der Deutschunterricht. ${ }^{38}$ Dem Lektor standen drei Stunden pro Woche zur Verfügung. Aus den Vorlesungsverzeichnissen lassen sich die von Šajatović behandelten Themen rekonstruieren: er hielt Vorlesungen »über die wichtigsten deutschen Sprachgesetze« und »Sprachformen«, unter besonderer Berücksichtigung der Bedürfnisse der künftigen Gymnasiallehrer. In seinem letzten Jahr an der Fakultät vermittelte er die Arbeiten des Grammatikers und Lexikografen Johann Christian August Heyse (1764-1829). Im Bereich der deutschen Literatur hielt Šajatović im Sommersemester 1876/77 Vorlesungen über die Literatur des Mittelalters und die Deutung von Goethes Faust. Daraufhin war die Rede von Schiller als Dramatiker, von der deutschen Literatur des 18. und 19. Jahrhunderts und von der Poetik. In einem Semester las er über die Wirkung von Heinrich Heine, Ludwig Börne und ihren Zeitgenossen und bot Erläuterungen zu den bedeutendsten neueren Werken. Seine Kenntnis der aktuellen Strömungen der deutschen Literaturwissenschaft wurde im Sommersemester 1884/85 durch die Anlehnung des Unterrichts an Wilhelm Scherers jüngst publizierte Geschichte der deutschen Litteratur (1883) unter Beweis gestellt. In seinem vorletzten Semester hielt er sogar Vorlesungen über die althochdeutsche Literatur. ${ }^{39}$

Aufgrund einer fortgeschrittenen Krankheit war Šajatović im Wintersemester 1885/86 nicht mehr imstande zu unterrichten. ${ }^{40}$ Als eine Rückkehr

Ebd. Es bleibt allerdings offen, ob die enge Freundschaft mit Franjo Marković, dem ersten Professor für Philosophie, Šajatović geholfen hatte, den Posten zu erhalten. Über das Verhältnis vgl. Tatarin: Između pjesničke imaginacije i estetičkih normativa, S. 214-215 sowie Šenoa: Iz mojih zapisaka, S. 393. Eine weitere offene Frage ist die Rolle des Bischofs Josip Juraj Strossmayer. Vgl. Jagić: Spomeni mojega života, Bd. 1, S. 104-108 und Šišić: Korespondencija Rački-Strossmayer, Bd. 1, S. 106, 132 u. 368.

37 AFFZG, Spisi, 1875, o. Nr., Bericht über Jacobi, Schlesinger und Šajatović. Neben der Teilnahme an der bekannten politischen Affäre 1870/71 (vgl. Jagić: Spomeni mojega života, Bd. 1, S. 104-108), die in den veränderten politischen Verhältnissen zum Zeitpunkt des Banus Ivan Mažuranić als ein Akt des Patriotismus angesehen wurde (vgl. Šišić: Korespondencija Rački - Strossmayer, Bd. 1, S. 368), hatte Šajatović in seiner Schulzeit an einem weiteren `Exzess` teilgenommen: der Zerschlagung von Fenstern und der Zerstörung der `Kaiseradler` nach dem Zusammenbruch des Bach'schen Regimes. Vgl. Krestić: Zagrebačke demonstracije i bekstvo Milana Makanca u Beograd.

38 AFFZG, Spisi, 6/1876; 26/1876; 27/1876; 29/1876; 54/1876.

39 Vgl. Akademičke oblasti, SoSe 1875/76 - SoSe 1884/85 und die teilweise erhaltenen Vorlesungsverzeichnisse in: AFFZG, Spisi, Vorlesungsverzeichnisse SoSe 1875/76 - SoSe 1884/85.

40 Obwohl in der Forschungsliteratur nur Sehstörungen erwähnt werden (vgl. Cuvaj: Građa $z a$ povijest školstva, S. 83), litt Šajatović vermutlich an einer Geisteskrankheit. Vgl. Šenoa: Iz mojih zapisaka, S. 393, 395-396; AFFZG, Spisi, 21/1886; 28/1886; 40/1886. 
ausgeschlossen schien, wurde Šajatović am 29. April 1886 aus dem Dienst entlassen. ${ }^{41}$

\section{Franjo Maixner: der erste Versuch einer Lehrstuhlgründung (1886)}

Professor Franjo Maixner erhielt im Mai 1886 den Auftrag, eine mögliche Lösung für die vakante Stelle vorzuschlagen. ${ }^{42}$ In der nächsten Sitzung des Fakultätsrates äußerte er seine Überzeugung, der Fakultätsrat müsse bei der Landesregierung die Gründung eines Lehrstuhls für deutsche Philologie an der Philosophischen Fakultät beantragen..$^{43}$ Es ist schwer zu sagen, warum es erst jetzt zu dieser Initiative kam. Möglicherweise hat man Rücksicht auf Šajatović genommen, für den aufgrund seiner Qualifikationen eine Bewerbung um die Professur ausgeschlossen war, dessen Lektorat jedoch aufgelöst worden wäre.

Maixners Auffassung nach entsprachen die damaligen Vorlesungen nicht den wirklichen Bedürfnissen des Universitätsunterrichts, geschweige denn den höheren Anforderungen der Wissenschaft, die für jede Universität am wichtigsten sein sollten. Er begründete seine Meinung mit der privilegierten Stellung des Deutschen im Schulunterricht und suchte Parallelen zu ähnlichen Universitäten in Österreich-Ungarn. Er betonte, die deutsche Sprache könne nicht wie andere lebende Sprachen gelehrt werden. Da Deutsch als Pflichtfach an Gymnasien und Realschulen unterrichtet werde, verfügten auch die schwächsten Hörer nach einem Gymnasium- oder Realschulabschluss wenigstens über Grundkenntnisse des Deutschen. Die anderen lebenden Sprachen würden dagegen an den Schulen entweder nicht gelernt oder seien nur Wahlfächer. Es störte ihn, dass es von allen an den Schulen unterrichteten Pflichtfächern nur für das Deutsche keinen Lehrstuhl gebe. Die vorgeschlagenen Änderungen könnten Qualität und Konkurrenzfähigkeit der Zagreber gegenüber anderen Universitäten in der Monarchie steigern. ${ }^{44}$ Es gebe, so Maixner, wenigstens zwei Vorteile bei der Einrichtung des Lehrstuhls.

Erstens könnte der germanistische Lehrstuhl auch für die Hörer der klassischen und slawischen Philologie von großem Nutzen sein, da sie mit der Teilnahme an Vorlesungen über deutsche Sprache und Literatur ihr

AFFZG, Spisi, 75/1886. Vgl. Cuvaj: Građa za povijest školstva, S. 83.

AFFZG, Spisi, 85/1886; 108/1886; Protokoll der Fakultätsratssitzung vom 19. Mai 1886, 130/1886. Franjo Maixner (Osijek 1841 - Zagreb 1903) war ordentlicher Professor für klassische Philologie (Latein) an der FFZG und Begründer des Seminars für klassische Philologie (1886). Vgl. Maixner, Franjo.

43 AFFZG, Spisi, 131/1886; Protokoll der Fakultätsratssitzung vom 3. Juli 1886, 179/1886.

44 AFFZG, Spisi, 135/1886. 
philologisches Wissen erweitern und eines Tages bessere Fachmänner in ihrem Bereich sein könnten. Seine Argumentation stützte sich auf den Vergleich mit >nichtdeutschen «niversitäten der Monarchie (mit Ausnahme der Universitäten in Wien und Graz sowie der deutschen Universität in Prag, wo oft zwei oder mehrere Professoren dieses Fach unterrichteten). Maixner betonte, deutsche Sprache und Literatur werde in Budapest von einem ordentlichen Professor betreut, in Klausenburg von einem außerordentlichen und an der tschechischen Universität in Prag von einem Privatdozenten und zwei Lektoren. Ordentliche Professuren gebe es auch in Lemberg, Krakau und Czernowitz. Er fügte hinzu, an einigen Universitäten existierten auch Seminare für deutsche Philologie, und zwar nicht nur an denjenigen, wo das Deutsche Unterrichtssprache sei (etwa in Wien, Graz oder Osnabrück); als Beispiele nannte er wiederum Czernowitz, Lemberg und Krakau. Mit Bedauern stellte Maixner fest, dass dieser Mangel nicht nur der wissenschaftlichen Ausbildung, sondern auch den sozialen und kulturellen Beziehungen innerhalb der Monarchie schade. ${ }^{45}$

Zweitens könne durch die Errichtung des Lehrstuhls der Mangel an Lehrkräften überwunden werden. Maixner behauptete, nur an wenigen Anstalten in Kroatien unterrichteten Lehrer mit bestandener Lehramtsprüfung im Fach Deutsch. Ihm schien es überflüssig zu erklären, was für Folgen dies für die Qualität des Unterrichts habe. Seiner Meinung nach war es für viele Kandidaten, die in Kroatien das Gymnasium abgeschlossen hatten, ziemlich schwierig und fast unmöglich die Lehramtsprüfung an einer externen Universität zu bestehen, was dazu führte, dass sie auf das Studium der Germanistik lieber verzichteten. ${ }^{46}$

Die von Maixner erwähnten Lehrstühle für deutsche Sprache an anderen Universitäten waren um 1850, also im Zuge der Umgestaltung des österreichischen Unterrichtswesens nach dem Revolutionsjahr 1848 errichtet worden, zuerst in Wien, Prag und Krakau. ${ }^{47}$ An der Universität Wien erfolgte 1868 mit der Einrichtung eines zweiten Ordinariats die Trennung des Faches in eine neuere und eine ältere Abteilung. ${ }^{48}$ Auch

an der im polnischen Sprachgebiet gelegenen Universität Krakau [...] wurde bereits 1850 ein Lehrstuhl für deutsche Sprache und Literatur gegründet, obwohl ein systematischer Unterricht in deutscher Sprache an den dortigen Gymnasien erst eingeführt worden war und von einem wissenschaftlichen Interesse der Studenten für dieses Lehrfach nicht die Rede sein konnte. ${ }^{49}$

47 Leitner: Die Anfänge der Germanistik in Österreich, S. 377.

48 Grabenweger: Germanistik in Wien, S. 1.

49 Leitner: Die Anfänge der Germanistik in Österreich, S. 377. 
Bei den Lehrstuhlgründungen spielten offenbar nicht nur wissenschaftsbezogene Überlegungen eine Rolle. Viel wichtiger war der "Einfluß, de[n] eine Förderung des Studiums der deutschen Sprache auf alle Nationalitäten Österreichs haben würde « ${ }^{50}$ Die Gründung des Lehrstuhls in Budapest war bereits 1784 erfolgt - mit der Aufgabe, »josefinistische Beamte mit guten Deutschkenntnisse auszubilden«. Erst nach dem Ausgleich 1867 begann sich die ungarische Germanistik als eine anerkannte Wissenschaft zu entwickeln. ${ }^{51}$

Nach längerer Diskussion wurde qua Stimmenmehrheit beschlossen, bei der Regierung einen Antrag auf Lehrstuhlgründung zu stellen. ${ }^{52}$ Franjo Marković, Tadija Smičiklas und Karel Zahradnik sprachen sich dagegen aus. Letzterer behauptete, es gebe »keine fähige Lehrkraft für die Professur der deutschen Sprache $«{ }^{53}$ Die Lehrstuhlfrage wurde in der Sitzung des Fakultätsrates am 12. März 1887 abermals aufgegriffen, die Antwort ließ jedoch einige Jahre auf sich warten. ${ }^{54}$

\section{Ivan Quiquerez: der Beinahe-Vater der kroatischen Germanistik (1887-1895)}

Ivan Quiquerez wurde am 19. April 1887 zum neuen Lektor ernannt. ${ }^{55}$ Bei seiner Ernennung betonte die kroatische Landesregierung, die Frage der Lehrstuhlgründung sei damit allerdings nicht gelöst. ${ }^{56}$

Bald kam es zum ersten Missverständnis zwischen dem Fakultätsrat und Quiquerez. Der Regel zum Trotz, dass der Lektor sowohl Grammatik als auch Literatur unterrichtet, entschied er sich dazu, im akad. Jahr 1887/88 nur$$
\text { (Regriar }
$$
gegründete FFZG. Er hörte drei Semester »historische und philosophische Kollegs ", setzte sein Studium in Wien fort und besuchte »historisch-geographische und philosophische Kollegs«. Schließlich verbrachte er zwei Semester in Graz. Anfang 1880 erwarb er das Recht, Geschichte und Erdkunde am ganzen Gymnasium in dt. und kroat. Unterrichtssprache zu lehren. Er unterrichtete an Gymnasien in Fiume (Rijeka) und Varaždin, danach an der Realschule in Zagreb. Um seine Deutschkenntnisse zu perfektionieren, verbrachte er das SoSe 1885/86 und das WiSe 1886/87 wieder in Graz. Die Lehramtsprüfung bestand er in Graz am 26. Februar 1887. Vgl. AFFZG, Spisi, 111/1895.

56 AFFZG, Spisi, 60/1887. 
literarische Themen zu behandeln (Geschichte der deutschen Literatur von Goethes Zeit bis zur Gegenwart, Goethes Hermann und Dorothea, Uhlands Balladen).$^{57}$ Im Wintersemester 1889/90 wollte er über die romantische Schule und Goethes Wilhelm Meisters Lehrjahre unterrichten. ${ }^{58}$ Dies veranlasste Dekan Marković zu der Frage, ob Quiquerez als Lektor überhaupt berechtigt sei, den Unterricht auf literarische Themen zu beschränken. ${ }^{59}$

Die darauffolgende Diskussion bestätigte, dass die Frage des universitären Deutschunterrichts noch immer offen war: Nach der Ansicht einiger Professoren sollten die Vorlesungen des Deutschen genauso wie die des Russischen, Ungarischen, Tschechischen usw. gestaltet werden. Andere waren sich des besonderen Status der deutschen Sprache in der kroatischen Gesellschaft bewusst und bestanden auf der Durchführung des von Quiquerez angekündigten Programms, da er mit einem Schwerpunkt auf grammatischen Themen die Hörer verlieren würde: man gehe doch nicht zum Lektor, um [deutsche] Grammatik zu lernen. ${ }^{60}$ Schließlich musste auch der Universitätsrektor Antun Franki reagieren: er bekräftigte, in den Vorlesungen müsse sowohl Literatur als auch Grammatik unterrichtet werden, um zu verhindern, dass andere Lektoren in die Fußstapfen von Quiquerez treten. ${ }^{61}$

Quiquerez scheint jedoch weiterhin auf dem Argument der besonderen Stellung des Deutschen beharrt zu haben. Als Gymnasial- und Realschullehrer mit zehnjähriger Unterrichtserfahrung fühlte er sich berufen, seine Einstellung zu diesem Fach zu äußern und die Aufmerksamkeit der Behörden auf seine Rolle zu lenken. Vier Jahre nach Maixners Vorschlag verfasste Quiquerez für den Fakultätsrat ein Schreiben ähnlichen Inhalts, jedoch mit ergänzender Argumentation. Er wies auf die positiven Auswirkungen des Erlernens von Fremdsprachen hin, ganz besonders des Deutschen als bedeutender Kultursprache, in einer Monarchie mit zehn Millionen Deutschen und mit wichtigen politischen, wissenschaftlichen und Handelsbeziehungen zum Deutschen Reich; einer Sprache zudem, die der Wissenschaft besonders wichtige Literaturbestände liefere. Abermals machte er von dem bekannten

57 Akademičke oblasti, WiSe 1887/88, S. 24; SoSe 1887/88, S. 24.

58 AFFZG, Spisi, 128/1889, I. Quiquerez an das Dekanat der FFZG, 26. Juni 1889.

59 AFFZG, Spisi, 174/1889. Es muss erwähnt werden, dass Marković seinem Intimus Šajatović (vgl. Tatarin: Između pjesničke imaginacije i estetičkih normativa, S. 215) diese Frage nicht gestellt hatte, obwohl dieser im SoSe 1882/83 und im SoSe 1883/84 ein vergleichbares Lehrangebot hatte. Vgl. AFFZG, Spisi, 36/1883; 7/1884.

60 AFFZG, Spisi, 174/1889.

61 AFFZG, Spisi, 285/1889. Das Kolleg über Goethes Wilhelm Meisters Lehrjahre wurde durch ein Kolleg zur dt. Grammatik ersetzt. Vgl. AFFZG, Spisi, 128/1889, I. Quiquerez an das Dekanat der FFZG, 15. Juli 1889 u. Akademičke oblasti, WiSe 1889/90, S. 24. 


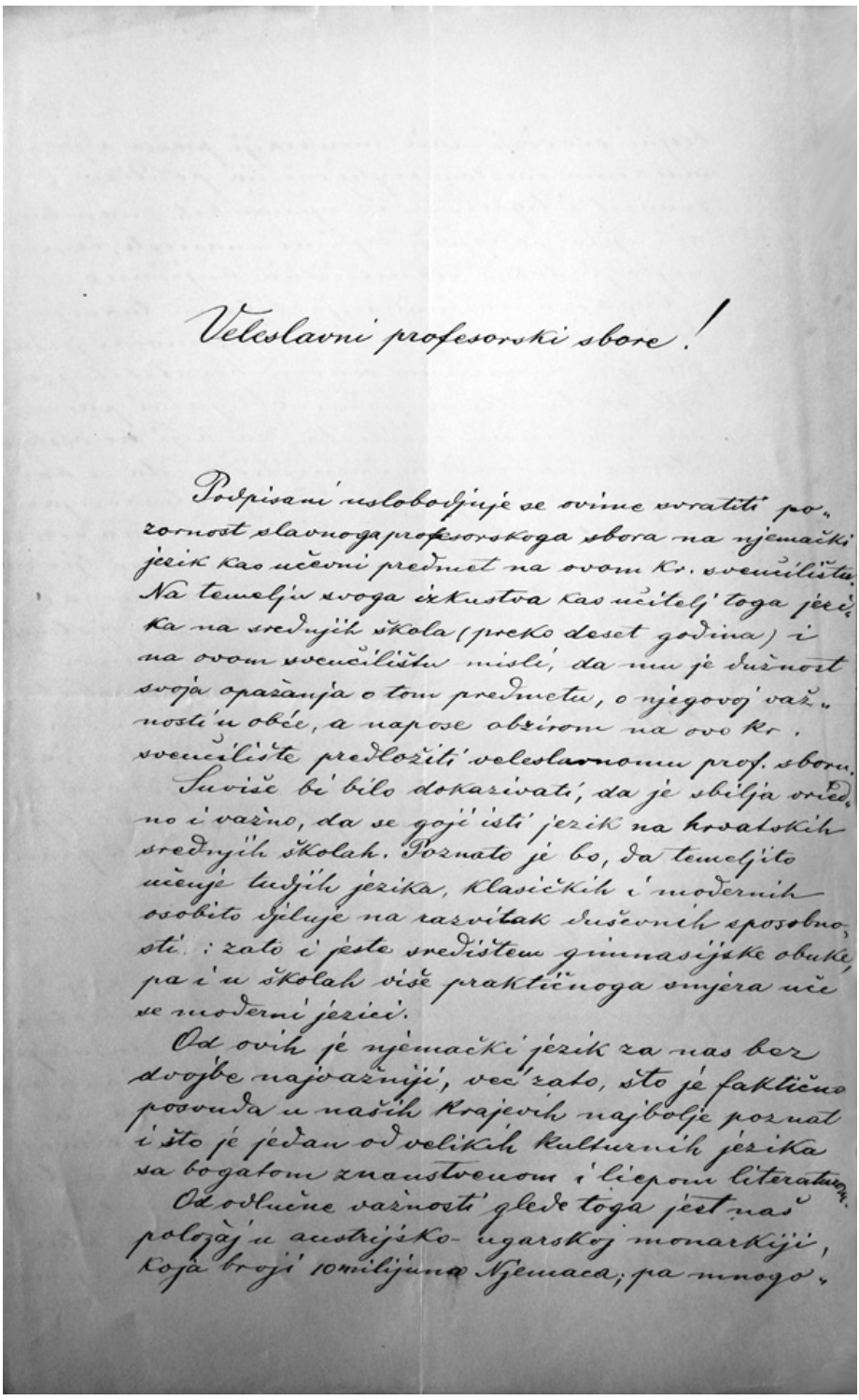

Abb. 2: Ivan Quiquerez' Initiative zur Gründung eines Lehrstuhls für deutsche Sprache (Quelle: AFFZG, Spisi, 90/1890)

zentralen Argument Gebrauch, das Deutsche sei das einzige Pflichtfach ohne Universitätslehrstuhl. Aufgrund der Stellung des Deutschen in Schule und Alltagskommunikation sei ein Deutschlektor jedoch vor komplexere Aufgaben gestellt als die Lektoren anderer Sprachen. Diesen könne er aber nur partiell nachkommen, da er ja auch an der Schule arbeiten müsse und mit drei - zudem von der unsicheren Vereinbarung zwischen Lektor und 
Hörern abhängigen - Wochenstunden keinen Professor ersetzen könne, der sich ausschließlich diesem Fach widmet. ${ }^{62}$

Während er auf eine Antwort wartete, stellte Quiquerez einen Antrag auf Weiterbildung im Bereich der deutschen Sprachwissenschaft an der Universität zu Berlin. Die Erlaubnis dazu wurde ihm Ende Januar 1891 erteilt. ${ }^{63}$ Isidor Kršnjavi, Sektionschef für Kultus und Unterricht der kroatischen Landesregierung, will Quiquerez aufgefordert haben, dort zu promovieren, um ihn später zum Professor ernennen zu können. ${ }^{64}$ Damals war es selbst einigen prominenten Professoren nicht möglich, eine solche Beurlaubung zu bekommen; ${ }^{65}$ Quiquerez dagegen hatte auch während seines Aufenthalts in Berlin Recht auf sein Lektorengehalt. ${ }^{66}$ Kršnjavi wird eine böse Überraschung erlebt haben, als Quiquerez ohne Doktortitel nach Zagreb zurückkehrte. Letzerer soll aber starke Unterstützung von der Frau des Banus Khuen-Héderváry genossen haben. ${ }^{67}$

Schließlich promovierte Quiquerez 1893 in Leipzig. ${ }^{68}$ Aufgrund seiner mit »admodum laudabile« bewertete Dissertation Quellenstudien zu Schillers Jungfrau von Orleans, erhielt Quiquerez »sine examine « seinen Doktortitel. ${ }^{69}$ Kršnjavi, den dies nicht vollständig befriedigte, forderte Quiquerez auf, sich in Wien zu habilitieren. ${ }^{70}$ Der Antrag auf eine erneute Beurlaubung wurde ihm Ende Januar 1894 genehmigt. ${ }^{71}$ Quiquerez verbrachte zwar ein Semester in Wien, erbrachte die verlangte Leistung jedoch nicht und enttäuschte Kršnjavi, der ihm wohl zum zweiten Mal versprochen hatte, ihn nach der Habilitation auf den Lehrstuhl zu berufen, somit aufs Neue. ${ }^{72}$ Quiquerez' Habilitationsschrift Über das Auftreten und Verschwinden moderner und

62 AFFZG, Spisi, 90/1890.

63 AFFZG, Spisi, 175/1890.

64 Kršnjavi: Zapisci, Bd. 1, S. 288.

65 Prof. Milivoj Šrepel hatte im Auftrag von Kršnjavi das Lehrbuch Institutionen des römischen Rechts übersetzt. Als Belohnung für die Arbeit, die niemand an der Juristischen Fakultät ausführen konnte, wurde ihm eine wissenschaftliche Weiterbildung in Paris in Aussicht gestellt. Kršnjavi hielt sich jedoch nicht an das Versprechen. Vgl. Vodnik: Profili i pojave, S. 207.

66 AFFZG, Spisi, 83/1892, Beschluss vom 19. März 1892.

67 Schon beim ersten offiziellen Mittagessen, an dem Kršnjavi als Sektionschef teilnahm, soll sie Kršnjavi aufgefordert haben, Quiquerez zum Universitätsprofessor zu berufen. Vgl. Kršnjavi: Zapisci, Bd. 1, S. 287.

68 Vgl. UAL, Gedruckte Dissertation, Quiquerez, 1893. I. Kršnjavi und B. Vodnik behaupteten fälschlicherweise, Quiquerez hätte in Graz promoviert. Vgl. Kršnjavi: Zapisci, Bd. 1, S. 288; Vodnik: Profili i pojave, S. 208.

69 UAL, Phil. Fak. Prom. 04484.

70 Kršnjavi: Zapisci, Bd. 1, S. 288.

71 AFFZG, Spisi, 345/1894; Brief von Quiquerez an das Dekanat der FFZG vom 4. April 1894; Protokoll der Fakultätsratssitzung vom 19. April 1894, 131/1894.

72 Kršnjavi: Zapisci, Bd. 1, S. 288. 
antiker Strophenformen in den Göttinger Musenalmanachen 1770-1804, ebenso wie seine Leipziger Dissertation, wurden von dem Wiener Professor Jacob Minor ${ }^{73}$ als bedeutende wissenschaftliche Arbeiten eingestuft. ${ }^{74}$ Quiquerez beendete sein Habilitationsverfahren jedoch nicht, da er sich der mündlichen Prüfung nicht unterziehen wollte. ${ }^{75}$

Der Lehrstuhl für deutsche Philologie wurde 1895 gegründet $^{76}$ und Quiquerez bewarb sich um die Professur. Die Meinungen der drei Gutachter waren geteilt, aber alle waren sich einig, dass er keineswegs zum Ordinarius berufen werden sollte. Tomo (Tomislav) Maretić und August Musić befürworteten seine Bewerbung, u.a. mit dem Hinweis auf seine bestandene Geschichtsprüfung und den möglichen Nutzen der allgemeinen Geschichte bei der Beschäftigung mit der Geschichte der deutschen Literatur, sowie auf das »hohe Alter « des (43-jährigen) Kandidaten. Da die Kompetenzen des Kandidaten im Bereich der Literatur noch zu entwickeln wären, empfohlen sie ihn nur für die außerordentliche Professur. ${ }^{77}$ Der dritte Referent, Milivoj Šrepel, hatte dagegen kein Verständnis für seine unvollendete Habilitation. ${ }^{78}$ Mit neun Stimmen für den Vorschlag von Maretić und Musić, zwei Stimmen dagegen und einer enthaltenen Stimme wurde die Bewerbung von Quiquerez am 30. März 1895 der Regierung empfohlen. ${ }^{79}$

In dem offiziellen Schreiben an die kroatische Landesregierung wurde noch einmal betont (wohl um die unvollendete Habilitation aufzuwiegen), wie gelungen die Arbeiten von Quiquerez seien; zudem gestalte sich eine Habilitation im Alter von 43 Jahren äußerst schwer, besonders in einem so umfassenden Fach, das jedoch sobald wie möglich im Fakultätsrat vertreten sein solle. Mangels anderer Kandidaten mit den gewünschten Qualifikationen sei Quiquerez die einzige Lösung. ${ }^{80}$ Quiquerez wurde am 22. Mai 1895 zum »außerordentlichen öffentlichen Professor für deutsche Sprache und Literatur an der Philosophischen Fakultät« ernannt ${ }^{81}$ und trat seinen neuen Dienst am 10. Juni an. ${ }^{82}$

Seinem weiteren Aufstieg schien nichts im Wege zu stehen. Weniger als zwei Monate nach seiner Ernennung schlug er vor, ein Seminar für

Bei Kršnjavi fälschlicherweise »Minov«. Vgl. Kršnjavi: Zapisci, Bd. 1, S. 288.

AFFZG, Spisi, 111/1895.

Ebd.

Bobinac: Odsjek za germanistiku, S. 175; Žmegač: Zur Geschichte der Germanistik in Kroatien, S. 112.

AFFZG, Spisi, 111/1895.

Šrepel war wahrscheinlich persönlich betroffen. Vgl. Anm. 65.

AFFZG, Spisi, 111/1895; 121/1895.

AFFZG, Spisi, 111/1895; Bericht vom 3. April 1895.

AFFZG, Spisi, 146/1895; 157/1895.

AFFZG, Spisi, 150/1895. 
deutsche Sprache zu gründen.$^{83}$ Die Initiative war jedoch verfrüht, zumal in zeitlicher Nähe zu aktuellen Diskussionen über eine Umstrukturierung der vorhandenen Seminare, und löste negative Reaktionen aus. ${ }^{84}$ Das Seminar konnte aus praktischen Gründen nicht eröffnet werden: es kamen dafür nur Studenten im zweiten Studienjahr in Frage, doch solche gab es an der Fakultät noch nicht. Auch protestierten einige Mitglieder des Fakultätsrates heftig gegen die Initiative, u.a. mit dem Argument, die Notwendigkeit einer Seminargründung - im Unterschied etwa zum Pädagogischen Seminar - sei noch nicht unter Beweis gestellt worden. Smičiklas äußerte sich explizit: Professor Quiquerez habe vor kurzer Zeit zu unterrichten begonnen; er solle erst zeigen, wie erfolgreich seine Vorlesungen seien ${ }^{85}$ Der Dekan suggerierte Quiquerez, seinen Vorschlag im nächsten Jahr zu präsentieren. Diese Gelegenheit würde sich Quiquerez jedoch nicht mehr bieten.

Im selben Jahr, in dem Quiquerez einen steilen Aufstieg erlebte, begann sein tiefer Fall. Kršnjavi wandte sich schließlich von ihm ab. Mit der Entscheidung des Sektionschefs vom 22. November 1895 wurde Quiquerez »vom Dienst und vom Gehalt suspendiert«, und zwar wegen »dem seinem Beruf abträglichen Verhalten und seiner für die angemessene Jugenderziehung geradezu gefährlichen Lebensweise innerhalb und außerhalb der Familie«. ${ }^{86}$

Nach seiner Suspendierung sank Quiquerez immer tiefer: Mitte Januar 1896 griff er Kršnjavi tätlich an, da er ihm die Hauptschuld für sein Schicksal zuschrieb. ${ }^{87}$ Er wurde »wegen des Verbrechens schwerer Körperverletzung “ verurteilt und am 16. Mai 1896 aus dem Dienst entlassen. ${ }^{88}$ Darüber hinaus wurde ihm sein Doktortitel für das Gebiet der Doppelmonarchie entzogen. ${ }^{89}$ Der Fakultätsrat beschloss in seiner Sitzung vom 6. Juni 1896, die Regierung um die Ausschreibung der vakanten Stelle zu bitten. ${ }^{90}$ Der einzige Kandidat war Stjepan Tropsch, ein junger Supplent vom Zagreber Unterstadtgymna-

AFFZG, Spisi, 187/1895; Protokoll der Fakultätsratssitzung vom 15. Juli 1895, 196/1895.

Luetić: Studenti Sveučilišta u Zagrebu, S. 163.

AFFZG, Spisi, 187/1895.

Vgl. Kršnjavi: Zapisci, Bd. 1, S. 106 u. 288; AFFZG, Spisi, 261/1895; 288/1895. Das Sittenurteil bezog sich auf eine angebliche Liebesaffäre des verheirateten Quiquerez.

Kršnjavi: Zapisci, Bd. 1, S. 106f. Vgl. auch Ein Attentat auf Sectionschef Dr. I. Kršnjavi.

AFFZG, Spisi, 192/1896; 225/1896. Nach seiner Entlassung gab Quiquerez Privatunterricht in Deutsch, Erdkunde, Geschichte und Französisch. Anfang Juli 1896 wurde er zum Lehrer an der Realschule in Semlin ernannt. Vgl. die Presseartikel Rehabilitierung und Rehabilitierung eines Universitäts-Professors; Kršnjavi: Zapisci, Bd. 2, S. 701. Über Quiquerez vgl. Vodnik: Profili i pojave, S. 207f; Vodnik: Ivan Quiquerez, S. 240; Pfanova: Naše sveučilište, S. 7.

Blecher: Das Leipziger Promotionsrecht zwischen 1409 und 1945, S. 201.

AFFZG, Spisi, 225/1896. 
sium. Damit begann die Universitätskarriere einer Person, die bis zu ihrem Tod 1942 der >spiritus movens der kroatischen Germanistik bleiben wird. ${ }^{91}$

\section{Stjepan Tropsch: Sachlichkeit und Gründlichkeit}

Kršnjavi hat nie seinen Beschluss bestritten, Quiquerez »loszuwerden, um Platz für einen fähigeren Mann zu schaffen «, was seiner Meinung nach keine »Ungerechtigkeit « war. ${ }^{92}$ Auch als Ex-Sektionschef behielt er großen Einfluss auf den Banus Khuen-Héderváry. ${ }^{93}$

In seiner Dissertation Flemings Verhältnis zur römischen Dichtung erforschte Tropsch, "was und wie der deutsche Dichter des 17. Jahrhunderts [...] in seinen Gedichten von den lateinischen Schriftstellern bezog $«{ }^{94}$ Die hoch gelobte Arbeit scheint auch sprachlich auf hohem Niveau gewesen zu sein: »[A]ußer in etlichen unbedeutenden Kleinigkeiten würde niemand merken, daß des Kandidaten Muttersprache nicht das Deutsche ist«, äußerte der eine Gutachter, ${ }^{95}$ während der zweite lediglich auf kleinere Fehler hinwies, die »einem Croaten leicht verzeilich sind $« .{ }^{96}$ So wurde Tropsch am 13. März 1894 zum Doktor der Philosophie promoviert, da er alle Rigorosa einstimmig mit Auszeichnung bestanden hatte. ${ }^{97}$

Im April desselben Jahres kehrte Tropsch nach Kroatien zurück und unterrichtete an mehreren Schulen. Nachdem er Anfang November 1895 in Graz die Lehramtsprüfung in deutscher Sprache und Literatur als Hauptund klassischer Philologie als Nebenfach bestanden hatte, wurde er im August 1896 zum wirklichen Lehrer am Zagreber Unterstadtgymnasium

91 Nach der Reifeprüfung, die er 1889 »mit Auszeichnung « bestand, wechselte Stjepan Tropsch (Vinkovci 1871 - Zagreb 1942) im selben Jahr nach Graz, um »Philosophie und insbesondere deutsche, zusätzlich noch klassische Philologie« zu studieren. In Graz blieb er bis zum SoSe 1892/93 und beschäftigte sich mit »Slawistik, Geschichte, specieller Philosophie und vergleichender Sprachwissenschaft «. Er besuchte Vorlesungen und war Teilnehmer an den Seminaren von Professoren Anton Emmanuel Schönbach, Bernhard Seuffert, Oswald Zingerle, Max Theodor von Karajan, Alois Goldbacher, Wilhelm Kergel, Gregor Krek, Adolf Bauer, Alexius von Meinong und Gustav Meyer. Vgl. UAG, Doktoratsakt von Stephan Tropsch, Curriculum vitae; AFFZG, Spisi, 58/1898, Curriculum vitae. Vgl. auch Spomenica o stopedesetogodišnjici Državne gimnazije u Vinkovcima, S. 205.

92 Kršnjavi: Zapisci, Bd. 2, S. 701.

93 Darüber, wie Kršnjavi die Gunst Khuen-Hédervárys erlangte, vgl. Artuković: Izidor Kršnjavi kao brodski zastupnik.

94 AFFZG, Spisi, 58/1898, Bericht von Kršnjavi.

95 UAG, Doktoratsakt von Stephan Tropsch, A. Schönbach: Gutachten über die Dissertation des Hrn. Stephan Tropsch.

96 UAG, Doktoratsakt von Stephan Tropsch, B. Seuffert: Die Dissertation des Stephan Tropsch.

97 AFFZG, Spisi, 58/1898, Curriculum vitae. 
berufen. Mit dem Regierungsbeschluss vom 13. Dezember 1895 wurde er zum Supplenten des Professors der deutschen Sprache und Literatur an der Universität Zagreb ernannt ${ }^{98}$ und begann im Sommersemester des akad. Jahres 1895/96 zu unterrichten.99

Der Unterricht sollte eigentlich im Semester davor beginnen, ${ }^{100}$ war jedoch wegen mangelndem Interesse ausgefallen. Tropsch hatte zwei Kollegs angeboten: "Geschichte der deutschen Literatur ausgehend von Lessing " (3 Wochenstunden) und »Lesung und Interpretation von Schillers Drama« (2 Wochenstunden). ${ }^{101}$ An der gesamten, 21 Jahre zuvor gegründeten Fakultät studierten damals 79 ordentliche und 19 außerordentliche Studenten und Studentinnen; ${ }^{102}$ nur drei davon hatte das Angebot von Tropsch zur Anmeldung bewogen: »zwei männliche und einen weiblichen $« .{ }^{103}$ Allerdings hatten bereits vor Unterrichtsbeginn die beiden »männlichen Hörer « andere Kollegs gewählt, während »der weibliche Hörer « nicht erschien. ${ }^{104}$ Im nächsten Semester, als der Unterricht tatsächlich begann, hatte Tropsch vier HörerInnen - darunter drei Frauen, die später eine wichtige Rolle im kroatischen Kulturleben einnehmen sollten: Camilla Lucerna als international angesehene Germanistin und Slawistin, Jagoda Truhelka als bedeutende kroatische Schriftstellerin und Natalija Wickerhauser als eine der ersten kroatischen Anglistinnen. ${ }^{105}$ Der einzige männliche Student war Josip (Josef) Rendi. ${ }^{106}$ Alle vier waren außerordentliche Hörer. Der Mangel an Studenten führte auch im Sommersemester 1896/97 zur Absage von Vorlesungen, da nur ein Student Tropschs Kolleg über die neuhochdeutsche Grammatik gewählt hatte. ${ }^{107}$

Als Supplent hielt Tropsch - wie damals auch an anderen philologischen Studienrichtungen üblich - literarische wie linguistische Kollegs. In seinem ersten Jahr unterrichtete er über die ältesten Zeugnisse deutscher Schriftkultur und konnte so mit anderen germanistischen Studiengängen in der

98 AFFZG, Spisi, 544/1895; Personalakte Stjepan Tropsch, Beschluss vom 13. Dezember 1895.

99 Das WiSe dauerte vom 1. Oktober bis Donnerstag vor dem Palmsonntag. Das SoSe begann am ersten Freitag nach Ostern und endete Ende Juli. Vgl. Luetić: Studenti Sveučilišta u Zagrebu, S. 159.

100 AFFZG, Spisi, 42/1896, 156/1896.

101 AFFZG, Spisi, 4/1896.

102 Spomenica o 25-godišnjem postojanju Sveučilišta Franje Josipa I. u Zagrebu, S. 138.

103 Die ersten Studentinnen wurden 1895 nur als außerordentliche Hörer zum Studium an der FFZG zugelassen. Ab 1901 konnten sie sich als ordentliche Hörer einschreiben. Über die ersten Studentinnen der FFZG von 1895 bis 1914 vgl. Luetić: Prve studentice Mudroslovnog fakulteta.

104 AFFZG, Spisi, 42/1896.

105 AFFZG, Imenici, Nr. 19; Sedlar: Germanistik in Kroatien, S. 282. Über Natalija Wickerhauser vgl. Vilke: Engleski jezik u Hrvatskoj, S. 9-10.

106 Josef Rendi (1861 Vág-Ujhely - 1934 Zagreb) wirkte als Oberkantor in den Gemeinden Troppau und Graz sowie ab 1895 in Zagreb. Vgl. Handbuch österreichischer Autorinnen und Autoren jüdischer Herrkunft, S. 1116.

107 AFFZG, Spisi, 58/1898, Curriculum vitae. 
Monarchie mithalten. ${ }^{108} \mathrm{Im}$ Wintersemester 1896/97 wagte sich Tropsch in Richtung Gegenwartsliteratur vor und kündigte das Kolleg »Leichte deutsche Literatur « an. Der Fakultätsrat beschloss jedoch, »dieses Kolleg passe nicht in den Vorlesungsrahmen eines Professors des Deutschen beziehungsweise seines Supplenten ${ }^{109}$ es musste daher durch ein anderes ersetzt werden.

In der gleichen Sitzung wurde eine weitere wichtige Frage besprochen: Franjo Marković wies auf die ungenügenden Deutschkenntnisse der Studierenden hin, die nicht imstande seien, sich der - für ihr Studium an der Philosophischen oder anderen Fakultäten jedoch unverzichtbaren deutschsprachigen wissenschaftlichen Literatur zu bedienen. Deswegen schlug er vor, wieder einen Lektor für das Deutsche zu ernennen oder ein Proseminar zu gründen. Dies wurde nicht angenommen, obwohl einige Professoren die Meinung vertraten, mit der Lehrstuhlgründung sei das Lektorat nicht abgeschafft worden. ${ }^{110}$

Anfang Juni 1897 stellte Tropsch einen Antrag auf Zulassung zum Habilitationsverfahren "als Privatdozent der deutschen Sprache und Literatur vom 12. bis zum 19. Jahrhundert «. Den Bewerbungsunterlagen fügte er drei schriftliche Abhandlungen bei: seine inzwischen veröffentlichte Dissertation, eine Abhandlung über die gewöhnlichsten Fehler im Deutschen und das Manuskript Wielands Don Sylvio und Cervantes' Don Quijote. ${ }^{111}$ Noch im selben Monat wurden als Gutachter der klassische Philologe Tomo Maretić und der im gleichen Jahr zur Universität zurückgekehrte Ex-Sektionschef und Kunsthistoriker Isidor Kršnjavi gewählt. ${ }^{112}$

In seinem Bericht gab Kršnjavi zwar viele Anregungen, wie Tropsch seine Abhandlungen erweitern und die Mängel beheben könnte, sein Urteil aber war positiv: er attestierte dem Kandidaten Ausdauer, Sorgfalt, Gewissenhaftigkeit und hervorragende Kenntnisse der lateinischen Literatur. ${ }^{113}$ Obwohl die Dissertation - in der Fleming als ein Kompilator mit $» 500$ geliehenen Orten von lateinischen Dichtern, [...] [davon] 240 von Horaz«

108 Bobinac: Odsjek za germanistiku, S. 175.

109 AFFZG, Spisi, Protokoll der Fakultätsratssitzung vom 27. Juni 1896, 288/1896.

110 Ebd.

111 AFFZG, Spisi, 58/1898, Habilitationsantrag.

112 AFFZG, Spisi, Protokoll der Fakultätsratssitzung vom 15. Juni 1897, 213/1897; 203/1897. Einige Tage vor der Sitzung, in der die Gutachter den Bericht hätten vorlegen sollen, trat Maretić mit der Begründung zurück, er sei für den Bereich der dt. Philologie nicht kompetent; im Habilitationskolloquium könne er nur Fragen zum Gotischen stellen, das Tropsch jedoch nicht in seinen Vorlesungsrahmen miteinbezogen habe. Vgl. AFFZG, Spisi, 203/1897, Erklärung von Maretić vom 20. Okt. 1897. Der späte Rückzug lässt vermuten, dass dafür andere Gründe als die angegebenen vorlagen.

113 Vgl. AFFZG, Spisi, 542/1898. 
präsentiert wurde - siebzig Jahre später als Paradebeispiel für "positivistische Übertreibungen bei der Suche nach Einfluss galt«, musste man dem Verfasser weiterhin »Planmäßigkeit und Geduld « zugestehen. ${ }^{114}$ Für seine Untersuchung musste Tropsch die Werke der beiden Dichter praktisch komplett auswendig können. ${ }^{115}$ Offensichtlich stellten die genannten Eigenschaften für Kršnjavi eine ausreichende Garantie dar, dass Tropsch all jenes erreichen könnte, was Quiquerez nicht gelungen war. Dank Kršnjavis Bericht und den Empfehlungen der Grazer Professoren Schönbach und Seuffert (der Gutachter seiner Dissertation) wurde Tropsch im Kolloquium zugelassen. Die Venia Legendi wurde ihm am 6. Februar 1898 erteilt. ${ }^{116}$

Tropsch wurde 1897 Mitglied der Prüfungskommission für Lehramtsprüfungen. Damit erfolgte die offizielle Gleichstellung der Zagreber Germanistik in der Lehrerausbildung mit den Lehrstühlen für deutsche Philologie an deutschen Universitäten der Monarchie, und die zukünftigen Deutschlehrer mussten zur Absolvierung der Lehramtsprüfung von nun an nicht mehr nach Wien oder Graz reisen. ${ }^{117}$ Für Sedlar belegt dies, "auf welch hoher Stufe sich schon damals die Agramer Germanistik befand «, da »für viele andere Studienfächer [der Zagreber Universität, Anm. d. Verf.] die Verpflichtung bestand, die Lehramtsprüfung an einer österreichischen, also deutschen Universität abzulegen «. ${ }^{118}$

Die Möglichkeit, die Kandidaten der Lehramtsprüfung in Zagreb zu unterziehen und sie zu Professoren der deutschen Sprache und Literatur zu ernennen, wirkte sich fördernd auf die kroatische Germanistik aus. ${ }^{119}$ Im Wintersemester 1897/98 wurden die ersten ordentlichen Studenten immatrikuliert: Ivan Grünwald und Gustav Šamšalović, die viele Jahre später auch selbst am Lehrstuhl für deutsche Philologie tätig sein würden. ${ }^{20} \mathrm{Um}$ 1900 betrug die Zahl der Studierenden der Germanistik bereits 20-25; ${ }^{121}$ ein Wachstum, das deutlich über dem Anstieg der Gesamtzahl ordentlicher Hörer an der Philosophischen Fakultät lag. ${ }^{122}$

114 Mojašević: Nemačko-jugoslovenske kulturne veze, S. 143.

115 Sedlar: Germanistik in Kroatien, S. 286.

116 AFFZG, Spisi, 423/1897; 448/1897; 57/1898; Personalakte Stjepan Tropsch, Beschluss vom 6. Februar 1898.

117 Bobinac: Odsjek za germanistiku, S. 175.

118 Sedlar: Germanistik in Kroatien, S. 282.

119 Ebd.

120 AFFZG, Imenici, Nr. 22.

121 Sedlar: Germanistik in Kroatien, S. 282.

122 Die Zahl der ordentlichen Hörer der FFZG betrug 89 im Jahr 1897/98 (WiSe); im Jahr 1901/02 waren es 111 (WiSe) bzw. 113 (SoSe). Vgl. Sveučilište Kraljevine Srba, Hrvata i Slovenaca, S. 257. 
Kršnjavi will die Ernennung von Tropsch zum Professor forciert haben. ${ }^{123}$ Seine Bewerbung wurde in der Sitzung des Fakultätsrates am 19. Dezember 1898 diskutiert. ${ }^{124}$ Mitglieder des Ausschusses für seine Ernennung waren Kršnjavi, Šrepel und Musić. In einem gemeinsamen, von Kršnjavi vorgelesenen Bericht wurde betont, dass Tropsch auch nach seiner Habilitation fleißig arbeite; seine neueren Arbeiten überträfen zwar nicht die älteren, doch dies sei allein mit seiner Arbeitsbelastung als Supplent zu erklären. Auch seine kürzeren Arbeiten seien als wissenschaftliche Abhandlungen zu betrachten. Ihre Empfehlung der Kandidatur wurde einstimmig angenommen. ${ }^{125}$ Tropsch wurde am 19. Februar 1899 zum außerordentlichen Professor der deutschen Sprache und Literatur ernannt. ${ }^{126}$

Das Lehrprogramm von S. Tropsch, oder zumindest das ambitionierte Programm in seinem Habilitationsantrag, war recht umfassend im Sinne des damals üblichen Kanons. ${ }^{127}$ Analyse und Interpretation der wichtigsten deutschen Volkslieder wurden besonders hervorgehoben. Hinzu kam eine kurze Übersicht über zeitgenössische Dichter. Germanistikstudenten mussten sich auch mit der mittelhochdeutschen Grammatik, insbesondere mit Sprachgesetzen, Sprachformen und der Syntax vertraut machen,»alles in jenem Umfang, der nach den österreichischen Prüfungsvorschriften für den Studenten der Germanistik erforderlich ist, um die ältesten literarischen Denkmäler richtig verstehen zu können«. Bezüglich der neuhochdeutschen Grammatik sollte besondere Aufmerksamkeit auf »die gewöhnlichsten Fehler « gelenkt werden. ${ }^{128}$

Vgl. auch AFFZG, Imenici, Nr. 18-34. Unter den außerordentlichen Hörern der FFZG waren im Zeitraum 1896/97 - 1901/2 pro Semester 1-3 Hörer der Germanistik zu verzeichnen.

123 Kršnjavi: Zapisci, Bd. 2, S. 750 und 757.

124 AFFZG, Spisi, 540/1898.

125 AFFZG, Spisi, 542/1898.

126 AFFZG, Spisi, 118/1899; Personalakte Stjepan Tropsch, Beschluss vom 9. Februar 1899. Kršnjavi behauptete später, Tropsch hätte seine Erwartungen als Universitätsprofessor nicht erfüllt. Vgl. Kršnjavi: Zapisci, Bd. 2, S. 757.

127 Zum 12. und 13. Jh.: Nibelungenlied und Gudrun, kurze Übersicht über die »Volksheldenlieder«, Epen von Hartmann von Aue, Wolfram von Eschenbach und Gottfried von Straßburg, Minnesang, Walther von der Vogelweide und Neidhart von Reuenthal. Zum 14. und 15. Jh.: Meistergesang, Volkslieder, Mysterienspiele und Fastnachtsspiele. Zum 16. Jh.: Martin Luther, Sebastian Brant, Thomas Murner, Hans Sachs und Johann Fischart. Zum 17. Jh.: Fleming und Opitz als Vertreter der Ersten Schlesischen Schule, Kirchenliteratur, Drama, Romane und Satire, Vertreter der Zweiten Schlesischen Schule und ihre Gegner. Zum 18. Jh.: Bodmer und Breitinger vs. Gottsched, Haller, Hagedorn, Anakreontiker; Klopstock, Wieland, Lessing und Herder sowie Schriftsteller des `Göttinger Hainbundes`, Sturm und Drang, Klassik: Goethe, Schiller und Jean Paul. Zum 19. Jh.: die romantische Schule, politische Dichtung, Schwäbische Schule, Junges Deutschland, Rückert, Platen, von den Österreichern v.a. Grillparzer.

128 AFFZG, Spisi, 58/1898. 
Im Antrag des Fakultätsrates an die Landesregierung vom 18. Juli 1902 wurde betont, die deutsche Sprache sei ein wichtiger Bestandteil der Universitätsausbildung und sollte daher im Fakultätsrat von einem ordentlichen Professor vertreten sein. ${ }^{129}$ Am 1 . November 1902 wurde Tropsch zum ordentlichen Professor berufen. ${ }^{130}$

\section{Josip Florschütz: im Schatten von Stjepan Tropsch}

In der Zeit, als Tropsch zum Privatdozenten und später zum außerordentlichen Professor ernannt wurde, trat noch eine Person in Erscheinung, die die Entwicklung der Zagreber Germanistik prägen würde. Der Sprachwissenschaftler Josip Florschütz ${ }^{131}$ reichte im Dezember 1898 seinen Habilitationsantrag in "Germanistik mit besonderem Schwerpunkt auf der deutschen Philologie« ein. ${ }^{132}$ Sechs Monate später wurde sein Antrag abgelehnt. Der entscheidende Kritikpunkt der beiden Gutachter betraf die vom Antragsteller vorgeschlagenen Kollegs, die nicht den ganzen Bereich der germanischen Philologie, sondern nur die deutsche Sprache und Literatur bis zum Beginn des 19. Jahrhunderts sowie gotische Grammatik mit Übungen umfassten. ${ }^{133}$ Offensichtlich hatten Florschütz und Tropsch recht unterschiedliche Vorstellungen vom Zuständigkeitsbereich der Germanistik. Obwohl auch Letzterer, im Geiste der Zeit, großen Wert auf die klassische deutsche Literatur legte, scheinen seine Vorlesungen auch das gesamte 19. Jahrhundert, auch zeitgenössische Dichter sowie »die wichtigsten neueren wissenschaftlichen Arbeiten auf dem Gebiet der neuhochdeutschen Literatur « berücksichtigt zu haben, was bei Florschütz offensichtlich nicht der Fall war. ${ }^{134}$

Allerdings war der Grundsatzkonflikt von einem persönlichen Konflikt begleitet, der auf den Seiten der Fachzeitschrift »Nastavni vjesnik « ausgetragen wurde. Florschütz verfasste 1899 eine umfangreiche, sehr kritische Besprechung des Orthographisch-grammatischen Wörterbuchs der deutschen Sprache,

129 AFFZG, Spisi, 510/1902; 521/1902.

130 AFFZG, Spisi, 771/1902; 802/1902; Personalakte Stjepan Tropsch, Beschluss vom 11. November 1902.

131 Josip Florschütz (Zagreb 1864 - ebd. 1916) studierte ab 1882 an der Universität Wien Slawistik, Germanistik und vergleichende Sprachwissenschaft sowie Musik. Er war Kroatischlehrer bei Erzherzog Johann Salvator (s.d.). Der 1887 promovierte Florschütz arbeitete ab 1895 als Lehrer in Zagreb und verfasste zahlreiche linguistische und musikwissenschaftliche Werke. Er war auch als Komponist tätig. Vgl. Florschütz, Josip.

132 AFFZG, Spisi, 516/1898.

133 AFFZG, Spisi, 307/1899.

134 AFFZG, Spisi, 58/1898. 
das Tropsch ein Jahr zuvor veröffentlicht hatte. Die Besprechung, in der eine Reihe von Mängeln aufgelistet wird, endet mit dem Fazit, ein solches Buch sollte den Schülern nicht in die Hände kommen und die Arbeit des Autors sei völlig überflüssig gewesen. ${ }^{135}$ In seiner schneidig-ironischen Antwort bedankt sich Tropsch unter anderem dafür, dass er auf einige Tippfehler und andere Kleinigkeiten aufmerksam gemacht wurde, die er in der zweiten Auflage seines Wörterbuchs berücksichtigen würde. ${ }^{136}$ Florschütz seinerseits beendete die Polemik mit dem Rat, bescheidener zu sein, statt sich an folgende Redewendung zu halten: Wem Gott gibt ein Amt, dem gibt er auch Verstand. ${ }^{137}$

Wohl wissend, dass die erwünschte Professur neben Tropsch nicht zu erlangen sei, änderte Florschütz sein Anliegen und wollte sich nun mit seiner Arbeit Zur Entstehung des schwachen Präteritums im Germanischen für das Gotische und Althochdeutsche habilitieren. ${ }^{138}$ Dem Antrag legte er Empfehlungen seiner Wiener Professoren Richard Heinzel und Franz Miklošič, außerdem der Professoren Vatroslav Jagić und Rudolf Meringer bei. ${ }^{139}$ Tropsch befürwortete diesen Antrag, ${ }^{140}$ wollte ihm den Habilitationsprozess jedoch nicht erleichtern. Den Vorschlag von Professor Vjekoslav Klaić, Florschütz vom Kolloquium zu befreien, da er ein älterer Lehrer sei und über schöne Zeugnisse der Wiener Professoren verfüge, lehnte Tropsch unter Hinweis auf die akademischen Vorschriften ab und setzte sich damit im Fakultätsrat durch. Das Kolloquium hätte in »einer der folgenden Fakultätssitzungen « stattfinden sollen. ${ }^{141} \mathrm{Da}$ es nach einem halben Jahr noch immer nicht stattgefunden hatte, beantragte Florschütz die Rückgabe seiner Dokumente, um sich für eine Professur an der Belgrader Hochschule bewerben zu können. ${ }^{142}$

Das Kolloquium fand schließlich Ende September statt, kurz vor Ablauf der einjährigen gesetzlichen Frist. ${ }^{143}$ Die Gutachter Šrepel, Tropsch und Maretić waren sowohl mit seinen Antworten als auch mit der Probevorlesung "über die Bildung des gotischen Perfekts im Bezug auf die anderen verwandten Sprachen ${ }^{144}$ sehr zufrieden und empfahlen Florschütz der

135 Florschütz: Dr. Stj. Tropsch, Ortografičko-gramatički rječnik njemačkoga jezika, S. 186.

136 Tropsch: Odgovor na recensiju, S. 191.

137 Florschütz: Odvraćak na Odgovor g. dra. Tropscha, S. 299.

138 AFFZG, Spisi, 657/1899, Habilitationsantrag.

139 Ebd. Meringer war Präsident der Indogermanischen Gesellschaft an der Wiener Universität, wo Florschütz seine überaus erfolgreiche Abhandlung vorgelesen hatte, die er nun als Habilitationsschrift einreichte.

140 AFFZG, Spisi, 657/1899, Bericht von Tropsch.

141 AFFZG, Spisi, Protokoll der Fakultätsratssitzung vom 15. Januar 1900, 47/1900.

142 AFFZG, Spisi, Antrag von Florschütz vom 11. Juli 1900.

143 AFFZG, Spisi, Protokoll der Fakultätsratssitzung vom 12. November 1900, 558/1900.

144 AFFZG, Spisi, 1/1901. 
Landesregierung. ${ }^{145}$ Die Venia Legendi erhielt er Mitte Januar 1901 und im Sommersemester 1900/01 begann er mit Vorlesungen zum Gotischen und Althochdeutschen (2 Wochenstunden). ${ }^{146}$

Florschütz schlug zwei neue Kollegs vor: »Über die gotischen und althochdeutschen Laute« und »Über die Formen im Gotischen und Althochdeutschen «. Im ersten sollten die Hörer einen Einblick in die relevante Literatur gewinnen und in die "ältesten literarischen Quellen, denen das Gotische und das Althochdeutsche entstammen «. Danach sollten sie sich mit der Entwicklung und Verwandtschaft der indoeuropäischen Sprachen vertraut machen. Im Mittelpunkt standen dabei die engen Verwandtschaften zwischen germanischen und italo-keltischen sowie slawisch-litauischen Sprachgruppen. Darauf folgte die Entwicklung der germanischen Sprachen. Das erste Kolleg endete mit der Vokal- und Konsonantenlehre.

Im zweiten Kolleg wurden Deklination der Substantive, Adjektive und Pronomen sowie Konjugation, Verbmodi und Zahlen behandelt. In seinen Vorlesungen verwendete Florschütz die neuesten Handbücher: Grundriß der vergleichenden Grammatik der indogermanischen Sprachen von Karl Brugmann und Berthold Delbrück (1886-1900), Urgermanische Grammatik (1896) und Gotisches Elementarbuch (1897) von Wilhelm Streitberg, Althochdeutsche Grammatik (1886) von Wilhelm Braune, Der indogermanische Akzent (1895) von Hermann Hirt und Grundriss der germanischen Philologie von Hermann Paul.

Während sich das Germanistikstudium in der gewünschten Richtung entwickelte, stellte sich erneut die Frage des Lektorats. Mit Tropschs $\mathrm{Zu}$ stimmung nahm der Fakultätsrat den Vorschlag an, das Lektorat wieder zu eröffnen, auch diesmal mit Blick auf die Studenten aller Studienrichtungen. ${ }^{147}$ Professor Vladimir Varićak begründete seine Initiative mit dem Hinweis auf die schwachen Deutschkenntnisse der Studenten, von den anderen Weltsprachen ganz zu schweigen. Es müsse ihnen die Möglichkeit gegeben werden, Deutsch auf dem Weg der Sprachpraxis zu erlernen, wie es auch schon in Russisch, Französisch, Italienisch, Englisch und Ungarisch der Fall sei. ${ }^{148}$ In der Debatte wies Đuro Šurmin auf die Sonderstellung des Deutschlektors hin: mit Blick auf den bestehenden Deutschunterricht an den Schulen dürfe er sich nicht auf den Elementarunterricht beschränken. ${ }^{149}$ Florschütz erklärte sich bereit, das Lektorat zu führen. ${ }^{150}$ 
Ein Jahr später kam der Banus der Forderung des Fakultätsrates nach und ernannte Florschütz zum Lektor; der Unterricht konnte im Sommersemester 1904/05 beginnen. ${ }^{151}$ Der damalige Dekan Varićak informierte alle Hörer, »deren Deutschkenntnisse unzureichend oder überhaupt nicht vorhanden sind «, über die Möglichkeit, durch praktische Vorlesungen und Übungen jene Sprachkenntnisse zu erwerben, die in kultureller Hinsicht für Kroatien am wichtigsten seien. Wie einst sollte der Lektor drei Wochenstunden unterrichten. Im ersten Semester nach der Wiedereröffnung des Lektorats hielt Florschütz Vorlesungen über die elementare Grammatik der deutschen Sprache (zwei Wochenstunden) sowie praktische Sprachübungen (eine Wochenstunde). ${ }^{152}$

Florschütz erhielt 1906 eine neue akademische Chance: Wieder einmal lenkte Kršnjavi die Geschicke eines Germanisten, indem er vorschlug, einen Lehrstuhl für vergleichende indogermanische Sprachwissenschaft zu errichten. Diese Wissenschaft habe sich, so Kršnjavi, in den 90 Jahren ihres Bestehens so weit entwickelt, dass sie unter allen philologischen Lehren die vornehmste Stelle einnehme und außerdem in letzter Zeit die zuverlässigste Helferin fast aller Wissenschaften geworden sei. Kein klassischer Philologe, Slawist oder Germanist könne ohne vergleichende indogermanische Philologie den Gegenstand seiner Wissenschaft richtig verstehen. Kršnjavi betonte, die Zagreber Universität müsse in dieser Hinsicht mit den deutschen und österreichischen Universitäten sowie der Budapester Universität mithalten. Die Einrichtung des Lehrstuhls für vergleichende Sprachwissenschaft sei umso notwendiger, als von 255 regelmäßigen Hörern der Philosophischen Fakultät mehr als hundert klassische Philologie, Slawistik oder Germanistik studierten. ${ }^{153}$ Die Einrichtung dieses Lehrstuhls sei somit im Interesse der wissenschaftlichen Reputation der Universität und der intensiveren wissenschaftlichen Ausbildung ihres philologischen Nachwuchses. ${ }^{154}$ Der erste außerordentliche Professor an dem neu gegründeten Lehrstuhl wurde 1908 Josip Florschütz; ein Jahr später wurde er zum ordentlichen Professor ernannt. ${ }^{155}$

151 AFFZG, Spisi, 220/1905; 222/1905; 316/1905.

152 AFFZG, Spisi, 238/1905. Nach Florschütz’ Tod 1916 nahm Gustav Šamšalović seinen Platz ein. 153 AFFZG, Spisi, 80/1906. Den offiziellen Angaben zufolge studierten 1905/06 an der FFZG im WiSe 239 regelmäßige und 12 außerordentliche Studenten und im SoSe 223 ordentliche und 9 außerordentliche. Vgl. Sveučilište Kraljevine Srba, Hrvata i Slovenaca, S. 250.

154 AFFZG, Spisi, 80/1906.

155 Bis zu seinem Tod (1916) lehrte Florschütz u.a. über Sanskrit, Albanisch, Gotisch und Litauisch. Seine Grammatik der kroat. Sprache (Gramatika hrvatskog jezika za ženski licej, preparandije i više pučke škole), war einflussreich im Standardisierungsprozess der kroat. Sprache in der ersten Hälfte des 20. Jhs. Vgl. Florschütz, Josip und Matasović: Napomena uz ovo izdanje, S. 267-270. 


\section{Seminar für deutsche Philologie}

Die volle Umsetzung des ambitionierten Programms, das Tropsch in seinem Habilitationsantrag skizziert hatte, ${ }^{156}$ bedurfte der formalen Gründung eines Seminars. Dies geschah im Februar 1904, als der Fakultätsrat den Vorschlag endlich annahm. ${ }^{157}$ Der damalige Dekan der Philosophischen Fakultät war allerdings kein anderer als Tropsch selbst. Bei der Dekanwahl im Studienjahr 1903/04 hatte dieser mit zehn von zwölf Stimmen einen eindeutigen Sieg errungen, seine Gegenkandidaten Marković und Maretić dagegen erhielten nur je eine Stimme. ${ }^{158}$ Der Posten des Dekans hat den Ausbau des germanistischen Lehrstuhls bzw. die Seminargründung sicherlich erleichtert. In kurzer Zeit, innerhalb von zehn Jahren nach der Übernahme des Lehrstuhls, erzielte Tropsch somit bedeutende Erfolge. Mit Recht wurde ihm der Titel »Vater der kroatischen Germanistik« zuteil. ${ }^{159}$

Während der Unterbreitung seines Vorschlags betonte Tropsch, dass im Gegensatz zu allen anderen Universitäten der Monarchie allein in Zagreb kein Seminar für deutsche Philologie exisitiere. Er habe bereits seit 1896 praktische Übungen gehalten und einige Hörer hätten schriftliche Aufgaben verfassen müssen.Seine Studenten könnten aber dazu nicht gezwungen werden, alles hänge von ihrem guten Willen ab. ${ }^{160}$ In einem Seminar dagegen wäre die Teilnahme an den Übungen sowie die schriftliche Ausarbeitung von Aufgaben für jedes Mitglied Pflicht. Die intensive selbständige wissenschaftliche Arbeit würde den Studenten in ihrem Lehrerberuf helfen und nur gute Deutschlehrer könnten die Leistungen der Jugend in diesem Fach wesentlich verbessern. Die Motivation der Seminarmitglieder würde außerdem, so Tropsch, sicherlich zur erhöhten Rate prämierter Höchstleistungen führen. ${ }^{161}$

Um die Deutschkenntnisse zusätzlich zu fördern, schlug Varićak vor, die Regierung zur Einführung von Stipendien an Germanistikstudenten im letzten, an einer deutschen Universität zu verbringenden Studienjahr aufzufordern. Doch für Tropsch kam dies nicht in Frage: seiner Meinung

156 AFFZG, Spisi, 58/1898.

157 AFFZG, Spisi, 132/1904.

158 AFFZG, Spisi, 332/1903; Dokument vom 25. Juli 1903.

159 Sedlar: Der Vater der kroatischen Germanistik, S. 6.

160 AFFZG, Spisi, 114/1904. Zur damaligen Studien- und Prüfungsordnung der FFZG vgl. Akademički propisi, S. 11-13.

161 Ebd. Den Seminarvorstehern stand eine Belohnung von $200 \mathrm{~K}$ zu. Die zwei besten Seminarteilnehmer erhielten je $50 \mathrm{~K}$. Die ersten im dt. Seminar ausgezeichneten Studenten waren Makso Bazala und Ljubica Kernic. Letztere wurde im selben Jahr auch für ihre Arbeit im kroat. Seminar prämiiert; sie setzte ihre Ausbildung in Wien und Leipzig fort. Vgl. AFFZG, Spisi, 583/1904; 590/1904 und Luetić: Prve studentice Mudroslovnog fakulteta, S. 193. 
nach hätte dies bedeutet, dass der Lehrstuhl völlig überflüssig wäre. Es sei besser, einzelne Studenten nach dem Studienabschluss zu fördern. Der Vorschlag von Varićak wurde daraufhin nicht mehr diskutiert. ${ }^{162}$

Das erste Seminar für deutsche Philologie - abgesehen von jenen in Tübingen und Heidelberg ${ }^{163}$ - wurde 1858 an der Universität Rostock gegründet. Es folgten 1873 die Universitäten in Straßburg, Graz und Lemberg, 1874 in Prag, 1876 in Czernowitz und Innsbruck. Aufgrund des persönlichen Widerstands eines Professors konnte ein Seminar für deutsche Philologie in Wien erst 1881 errichtet werden. ${ }^{164}$ Mit der Entscheidung der kroatischen Landesregierung wurde am 25. Februar 1904 das Seminar für deutsche Philologie in Zagreb gegründet, der Unterricht begann schon im Sommersemester 1903/04. ${ }^{165}$ Artikel 1 der genehmigten Statuten trennte den Seminarunterricht eindeutig von der Lektorentätigkeit, worauf Tropsch von Anfang an bestanden hatte. ${ }^{166}$ Den Statuten zufolge war das Seminar für deutsche Philologie ein Universitätsinstitut, verbunden mit der philosophisch-historischen Abteilung der Philosophischen Fakultät. Seine Aufgabe bestand in der Einführung und praktischen Einübung künftiger Deutschlehrer in die selbständige wissenschaftliche Arbeit im Bereich der deutschen Philologie, um sie auf diesem Wege für Spitzenleistungen zu befähigen. Die für alle Studenten (auch für Nichtteilnehmer des Seminars) offenen und kostenlosen, auf zwei bis drei Wochenstunden veranschlagten Seminarübungen waren für eine vielseitige Auslegung ausgewählter deutscher Literaturdenkmäler der alten und der neuen Zeit sowie für Vorträge über Grammatik und Literatur zum Zwecke der pädagogisch-methodischen Ausbildung vorgesehen. Die ausnahmslos auf Deutsch zu verfassenden schriftlichen Arbeiten dienten dem Nachweis von Fleiß, Wissen und kritischem Denkvermögen. Mündliche Interpretationen und Vorträge hatten alle Seminarmitglieder der Reihe nach zu halten. ${ }^{167}$

Das Seminarkonzept von Tropsch folgte offenbar dem Konzept seines Mentors Anton Emanuel Schönbach, der die Statuten für das deutsche Seminar in Graz ausgearbeitet hatte. Die 1873 verfassten Statuten des ersten österreichischen Seminars für deutsche Philologie sahen Übungen zur neueren deutschen Literatur vor. ${ }^{168}$ Von den österreichischen Universitäten folgte

162 AFFZG, Spisi, 114/1904.

163 Sie dienten nicht ausschließlich der dt. Philologie. Vgl. Leitner: Die Anfänge der Germanistik in Österreich, S. 383 und 384.

164 Leitner: Die Anfänge der Germanistik in Österreich, S. 384.

165 AFFZG, Spisi, 159/1904.

166 AFFZG, Spisi, 132/1904.

167 AFFZG, Spisi, 159/1904, Statuten des Seminars für dt. Philologie.

168 Obwohl $^{\text {bis zum Ende de }}$ 19. Jhs. fast an allen dt. und öst. Universitäten Extraordinariate oder Ordinariate für die neuere Literatur geschaffen wurden, sah sich das `Neue Fach` oft benachteiligt. 
in dieser Hinsicht nur Czernowitz dem Beispiel von Graz. ${ }^{169}$ In Zagreb sollte die Aufmerksamkeit darüber hinaus auf den Einfluss der deutschen auf die kroatische und serbische Literatur gerichtet werden. ${ }^{170}$ Außerdem gelang es dem Seminarvorsteher Stjepan Tropsch, eine sorgfältig aufgebaute Bibliothek zu schaffen, in der den Studierenden um 1940 etwa 3500 germanistische Titel zur Verfügung standen. ${ }^{171}$

Neben der Universitätsarbeit versuchte Tropsch auch den Gymnasialunterricht zu verbessern; außerdem rezensierte er im Auftrag der kroatischen Regierung deutsche Lesebücher und Wörterbücher. ${ }^{172}$ Er war Verfasser des bereits erwähnten Orthographisch-grammatischen Wörterbuchs sowie wissenschaftlicher Abhandlungen zu unterschiedlichen Themenstellungen wie etwa: die Beziehung zwischen Philologie und Logik an Mittelschulen, die deutsche Volksetymologie, Gustav Freytags Bedeutung, Christopf Martin Wielands Don Sylvio, Friedrich Justus Riedels Lied eines alten Croaten u.a. Obwohl nicht sehr umfangreich, ist sein Text Althochdeutsch, Mittelhochdeutsch und Neuhochdeutsch aus dem Jahr 1903 ein wichtiger Beitrag zur Standardisierung der kroatischen wissenschaftlichen Terminologie im germanistischen Bereich. $\mathrm{Zu}$ der in seiner Dissertation zu Fleming angewandten Methode der Einflussforschung kehrte Tropsch in Texten über die deutschen Vorbilder der kroatischen Schriftsteller Matija Antun Reljković und Matija Magdalenić zurück. Danach widmete er sich der Erforschung deutsch-kroatischer bzw. deutsch-südslawischer Literaturbeziehungen. ${ }^{173}$

Für die damaligen Verhältnisse nicht unbedeutend war seine Initiative im Oktober 1900, als er der Landesregierung den Vorschlag einer von ihm herauszugebenden Buchreihe deutscher Klassiker in kroatischer Übersetzung unterbreitete. Die Regierung lehnte seinen Vorschlag allerdings ab, da sie nur Bücher für die Schülerausbildung in Auftrag geben konnte. Sie stellte jedoch eine Belohnung sowie eine Empfehlung bei den Schulleitern der kroatischen Schulen in Aussicht, wenn er die geplante Reihe in eigener Auf-

Nach Angaben von Wilhelm Scherer, der 1879 eine anonyme Betrachtung über die österreichische Universitätsgermanistik veröffentlichte, kamen bspw. auf 4,10 Stunden älterer Literatur in Graz, 3,17 in Prag, 5,57 in Innsbruck und 3,16 in Czernowitz je eine Stunde Vorlesungen aus neuerer Literatur. Leitner fügt hinzu: »Während unter den Vorlesungen über die Literatur des Mittelalters auffallend viele Spezialkollegien zu finden waren, hatten die Kollegien über die neuere Zeit vorwiegend Übersichtscharakter und faßten unter dem Titel `Geschichte der neueren deutschen Literatur< die literarischen Erscheinungen des 18. oder 19. Jahrhunderts zusammen.« Vgl. Leitner: Die Anfänge der Germanistik in Österreich, S. 382.

169 Leitner: Die Anfänge der Germanistik in Österreich, S. 384.

170 AFFZG, Spisi, 159/1904, Statuten des Seminars für dt. Philologie.

171 Sedlar: Geschichte der Germanistik, S. 283.

172 AFFZG, Spisi, 282/1902.

173 Vgl. AFFZG, Personalakte Stjepan Tropsch, »Popis stručnih radova Dra Stjepana Tropscha«. 


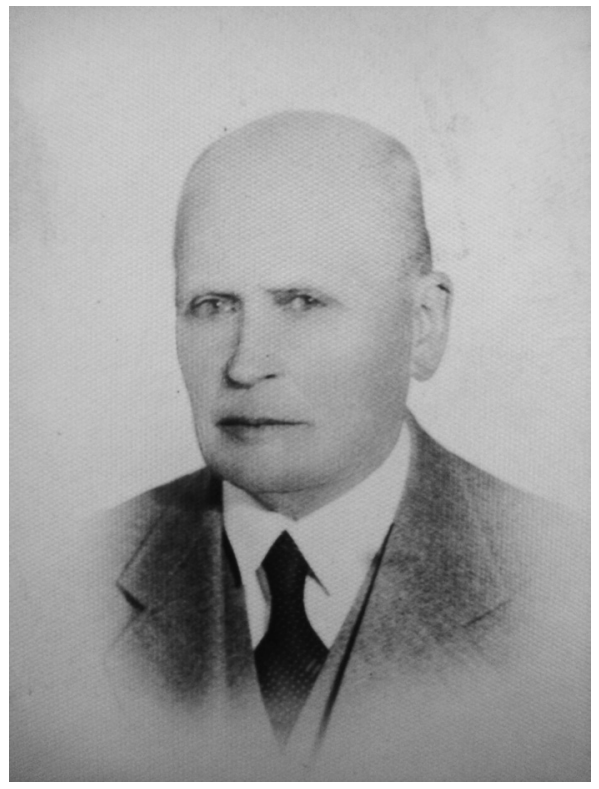

Abb. 3: Stjepan Tropsch (Quelle: AFFZG, Personalakte Stjepan Tropsch)

lage publiziert - allerdings für nur fünf Titel und nur für die bedeutendsten Werke. ${ }^{174}$ Anfang Januar 1902 reichte Tropsch bei der Regierung die von ihm betreute und kommentierte kroatische Ausgabe von Lessings Lustspiel Minna von Barnhelm ein. ${ }^{175}$ Tropsch erhielt die versprochenen 200 Kronen, doch die Regierung war mit seiner Leistung nicht ganz zufrieden. ${ }^{176}$ Diese Kritik mag Tropsch demotiviert haben; doch die Arbeit an der Buchreihe brach er vermutlich wegen Zeitmangel ab: nach 1906 musste er neben seinen Universitätspflichten auch die eines Abgeordneten des kroatischen Landtags erfüllen. Die Beziehung zur Politik war wohl auch vor seinem Eintritt in den Landtag eng gewesen. Um die großen persönlichen und institutionellen Erfolge zwischen 1895 und 1905 erzielen zu können, musste Tropsch gute Beziehungen zur Landesregierung pflegen. Sie entschied nicht nur über die Verteilung der Finanzmittel an Fakultäten und Lehrstühle, sondern hatte laut Universitätsgesetz von 1894 einen entscheidenden Einfluss auf alle Berufungen an der Universität. ${ }^{177}$

174 AFFZG, Spisi, 495/1900.

175 Vgl. Lessing: Minna von Barnhelm; AFFZG, Spisi, 18/1902.

176 AFFZG, Spisi, 233/1902.

177 Spomenica o 25-godišnjem postojanju Sveučilišta Franje Josipa I. u Zagrebu, S. 195-216, bes. 196f. u. 215. Mehrere Dokumente im Archiv der FFZG belegen Tropschs aktive Unterstützung der Regierungspolitik an der Fakultät. Zur Habilitation von Đuro Šurmin bzw. die im 


\section{Fazit}

Die Anfänge des universitären Deutschunterrichts an der Philosophischen Fakultät in Zagreb können als eher bescheiden bezeichnet werden. Trotz der besonderer Rolle der deutschen Sprache in der kroatischen Gesellschaft der zweiten Hälfte des 19. Jahrhunderts, wurde sie - wie die anderen lebenden Sprachen, mit Ausnahme der kroatischen und der im Rahmen der slawischen Philologie gelehrten Sprachen - nur sfür praktische Zwecker unterrichtet. Doch schon der erste Deutschlehrer Julije Šajatović sah ein, dass die Gestaltung des Deutschunterrichts im Vergleich zum Ungarischen anders aussehen musste. Zehn Jahre nach der Gründung des Lektorates und nach der Entlassung des schwer erkrankten Šajatović begann das Engagement mehrerer Akteure um die Errichtung des Lehrstuhls für deutsche Philologie. Franjo Maixner, der 1886 als erster diesen Vorschlag einbrachte, betonte, dass die bisherigen Vorlesungen den wirklichen Bedürfnissen des Universitätsunterrichts, geschweige denn den höheren Anforderungen der Wissenschaft, nicht mehr entsprachen. Auch der neue Deutschlehrer Ivan Quiquerez stimmte dem zu, doch der Lehrstuhl wurde erst 1895 gegründet. Quiquerez wurde kurz nach seiner Ernennung zum außerordentlichen Professor entlassen; die Leitung des Lehrstuhls übernahm Stjepan Tropsch, der heute als Gründungsvater der kroatischen Germanistik gilt. Obwohl die Lehrstuhlgründung in Zagreb erst 45 Jahre nach der Gründung des ersten Lehrstuhls in der Habsburgermonarchie erfolgte, wurde die Zagreber Germanistik in der Lehrerausbildung sehr schnell mit den deutschen Universitäten der Monarchie gleichgestellt (1897). Da die Hörer von nun an die Lehramtsprüfung für dieses Fach auch in Zagreb bestehen konnten, begann ihre Zahl allmählich zu wachsen. Seine hervorragenden Berufsqualifikationen nutzend und sich gekonnt den politischen Strömungen anpassend, gelang es Tropsch in den ersten zehn Jahren seiner Tätigkeit, den Organisationsaufbau der Zagreber Universitätsgermanistik abzuschließen.

Zwischen der Eröffnung des Lektorats für deutsche Sprache (1876) und der Gründung des Lehrstuhls für deutsche Philologie (1895) verschob sich der Fokus von der Entwicklung der praktischen Deutschkenntnisse auf die wissenschaftliche Beschäftigung mit germanistischen Inhalten vom Mittelalter bis zur Frühen Neuzeit sowie, in geringerem Maße, mit der zeitgenössischen Literatur des 19. Jahrhunderts, im Einklang mit den

Anschluss daran erfolgte Berufung an den Lehrstuhl für kroat. Sprache im Jahr 1901 sowie zur Habilitation des Historikers Dane Gruber vgl. AFFZG, Spisi, 551/1901; 234/1901; Protokoll der Fakultätsratssitzung vom 27. Juni 1902, 465/1902; 332/1903; Dokument vom 25. Juli 1903. Vgl. auch Vodnik: Profili i pojave, bes. S. 237. 
aktuellen Entwicklungen in der mitteleuropäischen Germanistik. Nachdem die institutionelle Konstituierung der Zagreber Germanistik abgeschlossen worden war, nach der Gründung des Lehrstuhls, des Seminars und der Seminarbibliothek, wurde auch das Interesse an der praktischen Seite der deutschen Sprache erneuert. In den veränderten Umständen erhielt auch das Lektorat für deutsche Sprache eine neue Bedeutung.

Für die Rekonstruktion der Institutionsgeschichte war es wichtig, die frühen Entwicklungsstadien des universitären Deutschunterrichts, die entscheidenden Akteure innerhalb und außerhalb des Faches sowie die gesamtgesellschaftlichen, die sprach- und die universitätspolitischen Kontexte zu berücksichtigen. Obwohl der analytische historiographische Ansatz einem Vergleich mit der Entwicklung in Graz, Wien, Leipzig, Berlin sowie Prag, Krakau, Lemberg und anderen mitteleuropäischen Städten Grenzen gesetzt hat, bedeutet das nicht, dass diese Beziehungen weniger wichtig sind. Sie sind, ganz im Gegenteil, noch systematisch zu untersuchen.

\section{Literaturverzeichnis}

\section{Ungedruckte Quellen}

Arhiv Filozofskog fakulteta u Zagrebu (Archiv der Philosophischen Fakultät in Zagreb) (AFFZG):

Spisi Dekanata Mudroslovnog fakulteta (Akten des Dekanats der Philosophischen Fakultät), 1874-1908

Imenici redovnih i izvanrednih slušača Mudroslovnog fakulteta (Namensverzeichnis der ordentlichen und außerordentlichen Hörer der Philosophischen Fakultät), Nr. 18-23; 43-50

Personalakte Stjepan Tropsch

Universitätsarchiv Graz (UAG), Doktoratsakt von Stephan Tropsch

Universitätsarchiv Leipzig (UAL), Phil. Fak. Prom. 04484

\section{Gedruckte Quellen}

Akademičke oblasti, osoblje i red predavanja u kr. sveučilištu Franje Josipa I u Zagrebu. Zagreb: Tisak Kralj. zemaljske tiskare 1874-1916.

Akademički propisi za porabu slušalaca u kr. hrv. sveučilištu Franje Josipa I. u Zagrebu. Zagreb: Tisak Kralj. zemaljske tiskare 1898.

Cuvaj, Antun (Hg.): Građa za povijest školstva kraljevinâ Hrvatske i Slavonije: od najstarijih vremena do danas. Bd. 6. Od 20. travnja 1869. do 31. svibnja 1875.: sa 55 slika i 67 životopisa. Zagreb: Trošak i naklada Kr. hrv.-slav.-dalm. zem. vlade, Odjela za bogoštovlje i nastavu 1911.

Dnevnik Sabora trojedne kraljevine Dalmacije, Hrvatske i Slavonije držana u glavnom gradu Zagrebu god. 1861. Zagreb: o.V. 1862. 
Ein Attentat auf Sectionschef Dr. I. Kršnjavi. »Agramer Zeitung« 15 (20.1.1896), S. 4; 29 (5.2.1896), S. 6f.; 73 (28.3.1896), S. 6.

Florschütz, Josip: Dr. Stj. Tropsch, Ortografičko-gramatički rječnik njemačkoga jezika. Zagreb 1898. »Nastavni vjesnik« 7 (1899), S. 177-186.

Florschütz, Josip: Odvraćak na Odgovor g. dra. Tropscha. »Nastavni vjesnik« 7 (1899), S. 298-302.

Izvěstje o Kraljevskoj višoj gimnaziji u Zagrebu koncem školske godine 1871/2. Zagreb: o.V. 1872.

Jagić, Vatroslav: Spomeni mojega života. Bd 1. 1838-1880. Beograd: Srpska kraljevska akademija 1930.

Kršnjavi, Iso: Zapisci: iza kulisa hrvatske politike. 2 Bde. Zagreb: Mladost 1986.

Lessing, Gotthold Ephraim: Minna von Barnhelm: vesela igra u pet čina. Zagreb: Knjižara L. Hartmana (Kugli i Deutsch) 1902.

Naredba kr. hrv.-slav.-dalm. zemaljske vlade, odjela za bogoštovlje i nastavu, od 10. listopada 1886. br. 6211, kojom se propisuje jedna naučna osnova za sve hrvatsko-slavonske realke. Zagreb: o.V. 1886.

Naučna osnova za srednje škole. Zagreb: Kr. zemaljska tiskara 1906.

Program kraljevske gimnazije u Zagrebu koncem školske godine 1866. Zagreb: o.V. 1866.

Program kraljevskoga maloga gimnazija u Karlovcu koncem školske godine 1869. Karlovac: Kraljevska mala gimnazija 1869.

Quiquerez, Ivan: Quellenstudien zu Schillers Jungfrau von Orleans. Eine litterarhistorische Untersuchung. Inaugural-Dissertation vorgelegt der hohen philosophischen Facultät der Universität Leipzig zur Erlangung der Doctorwürde von Ivan Quiquerez k. Professor aus Agram. Leipzig 1893 [Universitätsarchiv Leipzig, Gedruckte Dissertation, Quiquerez, 1893].

Pirch, Otto von: Caragoli. Bd. 1: Ungarn, Militairgrenze, Slavonien, Croatien. Berlin: In der Haude und Spenerschen Buchhandlung 1832.

Rehabilitierung. »Agramer Zeitung« 166 (21.7.1896), S. 3.

Rehabilitierung eines Universitäts-Professors. »Tages-Post « 166 (21.7.1896), S. 3.

Spomenica o 25-godišnjem postojanju Sveučilišta Franje Josipa I. u Zagrebu 1874 - 1899. Zagreb: Akademički senat 1900.

Spomenica o stopedesetogodišnjici Državne gimnazije u Vinkovcima 1780-1930. Osijek: Prva hrvatska dionička tiskara 1930.

Sveučilište Kraljevine Srba, Hrvata i Slovenaca u Zagrebu 1874-1924. Spomenica Akademičkoga senata. Zagreb: Tisak zaklade tiskare Narodnih novina 1925.

Šenoa, Milan: Iz mojih zapisaka. In: Autobiografije hrvatskih pisaca. Hg. Vinko Brešić. Zagreb: AGM 1997, S. 393-409.

Šidak, Jaroslav (Hg.): Spomenica u povodu proslave 300-godišnjice Sveučilišta u Zagrebu. Bd. 1. Zagreb: Sveučilište u Zagrebu 1969.

Šišić, Ferdo (Hg.): Korespondencija Rački - Strossmayer: o stogodišnjici rođenja Franje Račkoga. Bd 1. Od 6. okt. 1860. do 28. dec. 1875. Zagreb: Jugoslavenska akademija znanosti i umjetnosti 1928.

Šulek, Bogoslav: Deutsch-kroatisches Wörterbuch (Němačko-hrvatski rěčnik). 2 Bde. Agram: Verlag der F. Suppan'schen Buchhandlung 1860.

Šulek, Bogoslav: Hrvatsko-njemačko-talijanski rječnik znanstvenog nazivlja. 2 Bde. Zagreb: Narodna tiskara dra. Ljudevita Gaja 1874-1875.

Tropsch, Stjepan: Odgovor na recensiju moga Ortografičko-gramatičkoga rječnika njemačkoga jezika. »Nastavni vjesnik« 7 (1899), S. 186-191. 


\section{Forschungsliteratur}

Artuković, Mato: Izidor Kršnjavi kao brodski zastupnik u Hrvatskom saboru 1884.-1887. »Scrinia Slavonica« 6 (2006), S. 217-233.

Batinić, Štefka; Vavra, Ivan: Fremdsprachenunterricht in den kroatischen Schulen im 20. Jahrhundert. In: Formen und Funktionen des Fremdsprachenunterrichts im Europa des 20. Jahrhunderts. Hg. Elmar Lechner. Frankfurt/M., Wien.: Peter Lang AG, Internationaler Verlag der Wissenschaften 2002, S. 23-37.

Bilington, Džejms: Ikona i sekira. Istorija ruske kulture, jedno tumačenje. Beograd: Rad 1988. Blecher, Jens: Das Leipziger Promotionsrecht zwischen 1409 und 1945 als konstitutives und prägendes Element der akademischen Selbstverwaltung. Diss. Halle-Wittenberg 2006. <http://sundoc.bibliothek.uni-halle.de/diss-online/06/06H046/t5.pdf> (Zugriff: 14.4.2015).

Bobinac, Marijan: Odsjek za germanistiku. In: Filozofski fakultet Sveučilišta u Zagrebu. Hg. Stjepan Damjanović. Zagreb: Filozofski fakultet 1998, S. 175-183.

Florschütz, Josip. In: Hrvatska enciklopedija. <http://www.enciklopedija.hr/Natuknica. aspx?ID=19943> (Zugriff: 6.5.2015).

Florschütz, Josip. In: Österreichisches Biographisches Lexikon. Bd. 1 (Lfg. 4, 1956), S. 330-331.

Glovacki-Bernardi, Zrinjka u.a. (Hgg.): Agramer. Rječnik njemačkih posuđenica u zagrebačkom govoru/ Wörterbuch der deutschen Lehnwörter in der Stadtsprache von Zagreb. Zagreb: Novi Liber 2013.

Grabenweger, Elisabeth: Germanistik in Wien. Zur Geschichte des Faches von 1848 bis 2000. <https://germanistik.univie.ac.at/fileadmin/user_upload/inst_germanistik/ Germanistik_in_Wien_Grabenweger.pdf $>$ (Zugriff: 11.10.2014).

Gross, Mirjana; Szabo, Agneza: Prema hrvatskome građanskom društvu. Zagreb: Globus 1992.

Handbuch österreichischer Autorinnen und Autoren jüdischer Herrkunft 18. bis 20. Jahrhundert. Bd. 2. München: Saur 2002.

Kessler, Wolfgang: Politik, Kultur und Gesellschaft in Kroatien und Slawonien in der ersten Hälfte des 19. Jahrhunderts. Historiographie und Grundlagen. München: R. Oldenburg Verlag 1981.

Krestić, Vasilije: Zagrebačke demonstracije i bekstvo Milana Makanca u Beograd. »Historijski zbornik«, Nr. 1, Jg. 15 (1962), S. 231-242.

Leitner, Erich: Die Anfänge der Germanistik in Österreich und die Gründung des ersten Germanistischen Seminars. In: Österreich in Geschichte und Literatur. Wien: Institut für Österreichkunde 1972, S. 376-388.

Luetić, Tihana: Prve studentice Mudroslovnog fakulteta kr. Sveučilišta Franje Josipa I. u Zagrebu. »Povijesni prilozi« 22 (2002), S. 167-207.

Luetić, Tihana: Studenti Sveučilišta u Zagrebu (1874-1914). Društveni život, svakodnevica, kultura, politika. Zagreb: Srednja Europa 2012.

Mádl, Antal: Deutsche Sprache und Germanistik in Ungarn zwischen Motivation und Gegenmotivation. In: Germanistik in Mittel- und Osteuropa. Hg. Christoph König. Berlin, New York: de Gruyter 1995, S. 256-270.

Maixner, Franjo. In: Hrvatska enciklopedija. <http://www.enciklopedija.hr/Natuknica. aspx?ID=19943> (Zugriff: 6.5.2015).

Matasović, Ranko: Napomena uz ovo izdanje. In: Josip Florschütz: Gramatika hrvatskog jezika za ženski licej, preparandije i više pučke škole. Zagreb: Ex libris 2002, S. 267-270.

Mojašević, Miljan: Nemačko-jugoslovenske kulturne veze. Studije i članci. Beograd: Izdavačko-informativni centar studenata 1974. 
Petrović, Velimir: Esekerski rječnik / Essekerisches Wörterbuch. Zagreb: FF-press 2008.

Pfanova, Dora: Naše sveučilište. "Profili i pojave« u Njivi sredinom marta 1926. "Novosti« (22.3.1926), S. 7.

Piškorec, Velimir: Germanizmi u govorima đurđevečke Podravine. Zagreb: FF-press 2005. Roksandić, Drago: Kontroverze o njemačkoj kulturnoj orijentaciji u hrvatskom narodnom preporodu: njemački jezik u hrvatskoj svakodnevici, 1835.-1848. »Historijski zbornik« 60 (2007), S. 65-81.

Salić, Tomo (Hg.): Vinkovački leksikon. Vinkovci: o.V. 2007.

Sedlar, Antun: Germanistik in Kroatien. "Deutsche Kultur im Leben der Völker«, 2. Heft, Jg. 16 (1941), S. 281-290.

Sedlar, Antun: Der Vater der kroatischen Germanistik. "Deutsche Zeitung in Kroatien« 137 (1943), S. 6.

Strecha, Mario: O pitanju utjecaja bečkog središta na kulturni identitet Zagreba u 19. stoljeću. »Radovi Zavoda za hrvatsku povijest « 26 (1993), S. 79-88.

Šidak, Jaroslav u.a.: Povijest hrvatskog naroda g. 1860 - 1914. Zagreb: Školska knjiga 1968.

Tatarin, Milovan: Između pjesničke imaginacije i estetičkih normativa (O Franji pl. Markoviću, uz sto i pedesetu obljetnicu rođenja). »Prilozi« 43/44 (1996), S. 211-236.

Taylor, Alan John Percivale: Habsburška monarhija 1809-1918. Zagreb: Znanje 1990.

Tropsch, Stjepan. In: Enciklopedija Jugoslavije. Bd. 8. Zagreb: Jugoslavenski leksikografski zavod 1971, S. 375.

Valentić, Mirko u.a. (Hgg.): Povijest Hrvata. Bd. 2. Od kraja 15. st. do kraja Prvoga svjetskog rata. Zagreb: Školska knjiga 2005.

Valentić, Mirko: Vojna krajina i pitanje njezina sjedinjenja s Hrvatskom 1849-1881. Zagreb: Školska knjiga u.a. 1981.

Vilke, Mirjana: Engleski jezik u Hrvatskoj: Pogled u prošlost, sadašnjost i budućnost. »Metodika« Nr. 14, Jg. 8 (2007), S. 7-16.

Vince, Zlatko: Putovima hrvatskoga književnog jezika. Lingvističko-kulturnopovijesni prikaz filoloških škola i njihovih izbora. Zagreb: Nakladni zavod Matice hrvatske 1990.

Vodnik, Branko: Ivan Quiquerez. »Jugoslavenska njiva« Nr. 7, Jg. 10 (1926), S. 240.

Vodnik, Branko: Profili i pojave (Prilozi za istoriju Filozofskog fakulteta u Zagrebu). "Jugoslavenska njiva« Nr. 6, Jg. 10 (1926), S. 205-208; Nr. 7, Jg. 10 (1926), S. 235-238.

Žmegač, Viktor: Zur Geschichte der Germanistik in Kroatien. In: Germanistik in Mittel- und Osteuropa. Hg. Christoph König. Berlin, New York: de Gruyter 1995, S. 111-120.

\section{Internetquellen}

Abteilung für Germanistik. In: Filozofski fakultet Sveučilišta u Zagrebu. <http://www.ffzg. unizg.hr/german/cms/index.php?option=com_content\&task=view\&id=37\&Itemid $=64 \&$ lang $=$ german $>$ (Zugriff: 29.12.2015).

Odsjeci i katedre Filozofskog fakulteta. In: Filozofski fakultet Sveučilišta u Zagrebu. <http:// www.ffzg.unizg.hr/odsjeci.html> (Zugriff 29.12.2015).

Ovo je deset najvećih hrvatskih fakulteta po broju studenata. In: srednja.hr. <http://www. srednja.hr/Studenti/Vijesti/Ovo-je-deset-najvecih-hrvatskih-fakulteta-po-brojustudenata $>$ (Zugriff: 29.12.2015). 